\title{
DeCisões RACIONALMENTE ARBITRÁRIAS NO DiREITO ADMINISTRATIVO*
}

\section{UM DOSSIÊ SOBRE ESTADO ADMINISTRATIVO}

ADRIAN VERMEULE ${ }^{\dagger}$

\begin{abstract}
Resumo: Como o Direito Administrativo deve lidar com a incerteza genuína, em que as probabilidades não podem ser associadas aos
\end{abstract}

* [N.T] Traduzido para o português, com a autorização do autor, por Maíra Almeida e revisado por Antonio Guimarães Sepulveda, do artigo Rationally Arbitrary Decisions in Administrative Law, de Adrian Vermeule, originalmente produzido em língua inglesa e publicado no Journal of Legal Studies, Vol. 44, S-2, 2015. Maíra Almeida é Mestra e Doutoranda em Direito pelo Programa de Pós-Graduação em Direito (PPGD) da Universidade Federal do Rio de Janeiro (UFRJ), Pesquisadora Visitante na Faculdade de Direito de Harvard, com apoio da Coordenadoria de Aperfeiçoamento de Pessoal de Nível Superior (CAPES) e da Comissão Fulbright, e Pesquisadora do Laboratório de Estudos Teóricos e Analíticos sobre Comportamento das Instituições (LETACI). Email: almeida.maira.1@gmail.com. Antonio Guimarães Sepulveda é Mestre pelo Programa de Pós-Graduação em Direito (PPGD) da Universidade Federal do Rio de Janeiro (UFRJ), Doutorando em Direito pela Universidade do Estado do Rio de Janeiro (UERJ), Professor da Universidade Federal Fluminense (UFF) e Pesquisador pelo Laboratório de Estudos Teóricos e Analíticos sobre o Comportamento Institucional (LETACI). E-mail: antonioguisep@gmail.com.

${ }^{\dagger}$ Professor Ralf S. Tyler, Jr. de Direito Constitucional da Harvard Law School. O presente artigo foi preparado para a conferência da Universidade de Chicago “Desenvolvendo a Política Regulatória no Contexto da Incerteza Profunda: Perspectivas Jurídicas, Econômicas e das Ciências Naturais", de 26 a 27 de abril de 2013. Agradeço aos participantes da conferência pelos comentários e ricos debates, especialmente a Jennifer Nou, David Barron, Yasmin Dawood, David Dyzenhaus, Richard Lazarus, Eric Posner e David Weisbach; e aos participantes da Faculdade de Direito de Harvard e da Universidade de Toronto. Agradeço também a Cormac Early e Samantha Goldstein pela excelente assistência na pesquisa. 
resultados? Eu argumento que há uma importante categoria de decisões de agências sob incerteza na qual ser arbitrário é racional. A arbitrariedade racional surge quando nenhuma razão de primeira ordem pode fundamentar a escolha da agência, embora a agência tenha válidas razões de segunda ordem para fazer determinada escolha. Quando essas condições prevalecem, até mesmo um jogo de "cara ou coroa" pode ser uma estratégia perfeitamente racional de tomada de decisão para agências. Os tribunais devem adotar uma postura de deferência às decisões racionalmente arbitrárias. Há um papel próprio para as cortes de garantir que agências tenham recursos adequadamente investidos na coleta de informações, o que pode dissipar a incerteza. Ainda assim, o valor de investimentos adicionais na coleta de informações, em alguns casos, será genuinamente incerto. Se assim for, os tribunais devem ter deferência às escolhas de segunda ordem das agências sobre investimentos informacionais pelos mesmos fundamentos que justificam a deferência às escolhas de primeira ordem sob incerteza feitas por agências.

Palavras-Chave: Agências; Incerteza; Razões de Primeira Ordem; Razões de Segunda Ordem; Arbitrariedade.

ABSTRACT: How should administrative law cope with genuine uncertainty, in which probabilities cannot be attached to outcomes? I argue that there is an important category of agency decisions under uncertainty in which it is rational to be arbitrary. Rational arbitrariness arises when no first-order reason can be given for the agency's choice, yet the agency has valid second-order reasons to make a particular choice. When these conditions obtain, even coin flipping may be a perfectly rational strategy of decision making for agencies. Courts should defer to rationally arbitrary decisions. There is a proper role for courts in ensuring that agencies have adequately invested resources in information gathering, which may dispel uncertainty. Yet in some cases the value of 
further investments in information gathering will be genuinely uncertain. If so, courts should defer to agencies' second-order choices about informational investments on the same grounds that justify deference to agencies' first-order choices under uncertainty.

KEYWORDS: Agencies; Uncertainty; First-Order Reasons; Second-Order Reasons; Arbitrariness. 


\section{SUMÁRIO:}

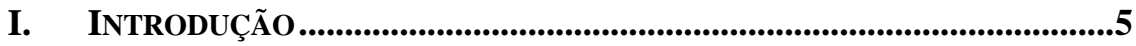

II. INCERTEZA, RACIONALIDADE E DIREITO _..................................................9

1. Administrative Procedure Act ........................................................10

2. National Environment Policy Act....................................................13

III. QUANDO AS RAZÕES SE ESGOTAM..............................................................14

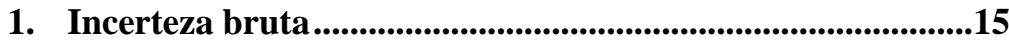

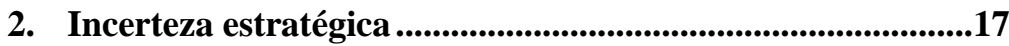

3. Reconhecendo que as razões se esgotam ..................................20

IV. OTIMISMO, PESSIMISMO E INCERTEZA ...............................................22

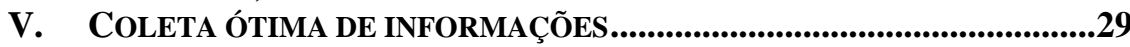

VI. DECISÕES RACIONALMENTE ARBITRÁRIAS .....................................33

1. Incerteza: uma solução institucional ........................................34

2. Como agências devem decidir? ................................................35

3. Incerteza, pretexto e inconsistência .........................................38

4. Do normativo ao descritivo ............................................................40

VII. CONCLUSÃO: AS AGÊNCIAS NA FRONTEIRA DA INCERTEZA ................42

VIII.REFERÊNCIAS............................................................................................43

\section{TABLE OF CONTENTS:}

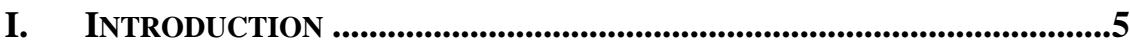

II. UNCERTAINTY, RATIONALITY, AND LAW .......................................9

1. The Administrative Procedure Act .........................................10

2. The National Environment Policy Act ........................................13

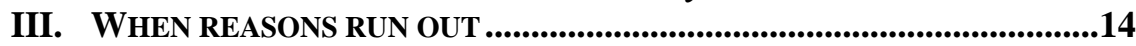

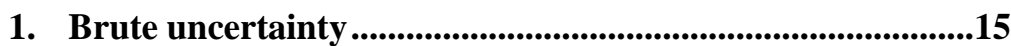

2. Strategic uncertainty ........................................................17

3. Recognizing when reasons have run out .................................20

IV. OPTIMISM, PESSIMISM, AND UNCERTAINTY ..........................................22

V. OPTIMAL INFORMATION GATHERING ....................................................29

VI. RATIONALLY ARBITRARY DECISIONS ...........................................33

1. Uncertainty: an institutional solution .....................................34

2. How should agencies decide? .........................................................35

3. Uncertainty, pretext, and inconsistency .....................................38

4. From normative to positive ..........................................................40

VII. CONCLUSION: AGENCIES AT THE UNCERTAINTY FRONTIER..............42

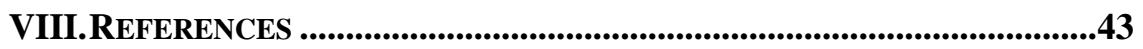


Se o [Board of Immigration Appeals ${ }^{1}$ propusesse restringir a classe de estrangeiros deportáveis elegíveis a pedir dispensa de remoção ao lançamento de uma moeda - se der cara, um estrangeiro pode se candidatar à dispensa; coroa, ele não pode -, nós poderíamos reverter a política em um instante. Isso porque a ação da agência deve se basear em "fatores relevantes", não arbitrários. Judulang v. Holder, 132 S. Ct. 476, 485 (2012), Judge Kagan.

O sentido em que estou usando o termo ["incerteza"] é aquele em que é incerta a perspectiva de uma guerra europeia, ou o preço do cobre e a taxa de juros daqui a vinte anos, ou a obsolescência de uma nova invenção, ou a posição dos proprietários de riqueza privada no sistema social em 1970. Sobre essas questões não há base científica em que se possa formar qualquer probabilidade calculável. Simplesmente não sabemos. No entanto, a necessidade de ação e de decisão nos obriga, como homens práticos, a fazer o nosso melhor para ignorar esse fato incômodo e comportar-se exatamente como deveríamos se tivéssemos o suporte de um bom cálculo de Bentham, composto por uma série de vantagens e desvantagens prospectivas, cada uma multiplicada pela sua probabilidade apropriada, à espera de ser somada.

KEYNES, John Maynard. The General Theory of Employment. The Quarterly Journal of Economics, Vol. 51, 2, 1937, p. 214.

\section{INTRODUÇÃO}

Como a lei deve lidar com a incerteza genuína de Knight, na qual as probabilidades não podem se relacionar com os resultados? ${ }^{2}$ No Estado

${ }^{1}$ [N.T.] Por uma tradução livre, trata-se do Conselho de Recursos de Imigração.

${ }^{2}$ Cf. KNIGHT, Frank. Risk, Uncertainty and Profit. Boston: Houghton Mifflin Co., 1921. Al-Najjar sugere que há uma tradução Bayesiana para os pontos que desejo tratar aqui. Cf. AL-NAJJAR, Nabil I. A Bayesian Framework for the Precautionary Principle. Journal of Legal Studies, Vol. 44, S-2, 2015. Embora eu até acredite que a abordagem bayesiana, em geral, repousa sobre bases arbitrárias, na medida em que existe um grande domínio de questões regulatórias e políticas sobre as quais probabilidades $a$ priori não têm fundamentação ou justificação epistêmicas, as afirmações que faço aqui não dependem dessa crença, e eu não tenho necessidade de assumir uma posição 
Administrativo moderno, a questão surge em dois níveis diferentes. No primeiro nível, as agências exercem a autoridade legal delegada para regulamentar, ainda que suas decisões regulatórias, com alguma frequência, devam ser tomadas sob incerteza genuína. No segundo nível, os tribunais apreciam decisões de agências tomadas sob incerteza e devem aplicar requisitos gerais do direito administrativa para a tomada de decisões racionais. Neste nível, a questão não é qual decisão sob incerteza seria correta, mas se a agência abordou a decisão de modo racional.

Vou me concentrar no segundo nível, perguntando como os tribunais revisam e deveriam revisar as decisões da agência sob incerteza. ${ }^{3}$ Aqui estão alguns exemplos recentes e reais dos problemas relevantes:

Espécies Ameaçadas. O secretário do interior, atuando pelo Fish and Wildlife Service, deve decidir se alistará o larto-de-chifres de cauda achatada como uma espécie ameaçada sob a Endangered Species Act. ${ }^{4} \mathrm{O}$ problema é que a metodologia anteriormente usada para estimar o número de lagartos em uma determinada área tem sido refutada e os

controversa dentro da teoria da decisão. Portanto, não tenho qualquer discussão com quem quiser entender minhas proposições em termos bayesianos.

${ }^{3}$ Uma questão diferente é como revisores não-judiciais, como o Office of Information and Regulatory Affairs (OIRA) [Escritório de Informações e Assuntos Regulatórios], devem abordar a tomada de decisão sob incerteza de agências. Acredito que o problema é omnipresente para o OIRA, mas tem havido certa tendência de revisores do OIRA a negar a própria existência de incerteza genuína, assumindo, em vez disso erroneamente na minha opinião - que probabilidades epistemologicamente justificadas podem ser atreladas a qualquer resultado possível. Entretanto, abordar esses assuntos aqui me levaria muito longe. Por ora, confino o tema aos problemas de revisão judicial da tomada de decisão sob incerteza de agências.

${ }^{4}$ [N.T.] Por meio de uma tradução livre, trata-se do Serviço de Pesca e Vida Selvagem e da Lei de Espécies Ameaçadas. O réptil referido acima é conhecido, na língua inglesa, como flat-tailed horned lizard e tem o nome científico de Phrynosoma mcallii. A Endangered Species Act criou, nos Estados Unidos, além de outras classificações administrativas das espécies, duas listas que ensejam especial proteção pelo governo. A mais rigorosa é a lista de espécies ameaçadas de extinção (endangered species), que protege espécies cujas populações, no todo ou em significativa porção, estão sob risco eminente de extinção. A segunda é a lista de espécies ameaçadas (threatened species), que também oferece cuidados especiais a espécies cujas populações caminhem naturalmente em direção a um quadro de potencial extinção em um futuro relativamente previsível. Portanto, o autor se refere a esta segunda lista ao discutir sobre a proteção do lagarto-de-chifres de cauda achatada.

3 JOURNAL OF INSTITUTIONAL STUDIES 1 (2017) 
métodos mais recentes ainda não estão operacionalizados. Em suma, ninguém possui qualquer base racional para estimar quantos lagartos existem. O que o secretário deve fazer? $\mathrm{O}$ que o Tribunal deve dizer que o secretário pode, não pode, ou deve fazer? ${ }^{5}$

Segurança Laboratorial. O Departamento de Energia quer abrir uma instalação de biossegurança nível 3 para manipular patógenos como o vírus da síndrome respiratória aguda grave no Lawrence Livermore National Laboratory. ${ }^{6}$ O quão séria é a possibilidade de patógenos escapem, tanto por causa de acidentes, quanto por ataques terroristas? Quantas análises, ou que tipo delas, tribunais devem exigir que o departamento conduza antes de autorizar que a instalação seja construída?7

Usinas de Energia Nuclear. A Nuclear Regulatory Commission tem de decidir se licencia as usinas de energia nuclear. ${ }^{8}$ Um dos pontos centrais dessa decisão é saber se os combustíveis nucleares gastos que estejam armazenados nessas instalações representam uma ameaça à saúde ou ao meio-ambiente. Os cronogramas relacionados extrapolam a imaginação, já que alguns dos materiais envolvidos têm períodos de meia-vida prolongados por centenas de milhares de anos. Como deve a comissão avaliar os possíveis danos? Tribunais revisores devem exigir que a agência use premissas cautelosas ou conservadoras sobre esses danos? ${ }^{9}$

Anuidades fixas indexadas ${ }^{10}$. A Securities and Exchange Commission (SEC)

${ }^{5}$ Cf. Tucson Herpetological Society v. Salazar, 566 F. 3d 870 (9th Cir., 2009).

${ }^{6}$ [N.T.] Por meio de uma tradução livre, trata-se do Laboratório Nacional Lawrence Livermore. A patologia referida acima é conhecida, na língua inglesa, como severe acute respiratory syndrome (SARS).

${ }^{7}$ Cf. Tri-Valley Cares v. U.S. Department of Energy, 671 F. 3d 1.113 (9th Cir., 2012).

8 [N.T.] Por meio de uma tradução livre, trata-se da Comissão de Regulação Nuclear.

${ }^{9}$ Cf. Baltimore Gas \& Electric Co. v. Natural Resources Defense Council, Inc., 462 U.S. 87 (1983).

${ }^{10}$ [N.T.] As anuidades representam um gênero de investimento presente no sistema financeiro norte-americano semelhante a alguns planos de previdência privada observados no Brasil. Trata-se de um depósito que investidores, na maioria dos casos aposentados, realizam em favor de uma instituição financeira, geralmente uma companhia de seguros, para que esta administre e arrende, comprometendo-se a pagar, em contrapartida, quantias anuais ao investidor no futuro por um tempo determinado, a fim de lhe assegurar uma receita periodicamente garantida. As anuidades admitem distintas espécies para cada perfil de investidor, podendo ser fixas ou variáveis, conforme os limites de flutuação para os valores anualmente recebidos, ou indexadas, se atrelada a algum índice representativo do mercado de ações especificamente (e.g. Dow Jones Industrial Average - DJIA, Nasdaq Composite - 
deve decidir se as anuidades fixas indexadas devem contar como "anuidades" na acepção das leis federais de valores mobiliários. ${ }^{11} \mathrm{~A}$ legislação ordinária exige da comissão que considere os efeitos de sua decisão na eficiência e na concorrência. A comissão acredita que a pior situação possível é a insegurança jurídica sobre se as anuidades fixas indexadas contam como "anuidades". Qualquer decisão nesse assunto promoverá competição. Mas a pergunta persiste: em que sentido ela deve decidir? ${ }^{12}$

A minha tese é que tribunais, com alguma frequência, desconhecem seu papel em casos como esses, em parte porque eles cometem erros conceituais sobre o que significa tomar decisões racionais sob incerteza. Procedimentalmente, as cortes exigem, às vezes, razões que não podem ser dadas. Sob circunstâncias de incerteza genuína, as razões se esgotam e uma exigência implacável por maiores fundamentações se torna patológica. ${ }^{13}$ Há uma categoria de decisões de agências em que ser arbitrário é racional, no sentido de que nenhuma razão de primeira ordem pode justificar a escolha, dentro de determinado domínio, por parte de uma agência, ainda que uma escolha ou outra seja inescapável, legalmente obrigatória, ou ambos. Em alguns casos, até mesmo "cara ou coroa" pode ser uma estratégia perfeitamente racional de tomada de decisão para agências (Não está claro se a opinião de Justice Elena Kagan, citada na epígrafe, deve ser entendida como uma afirmação de que "cara ou coroa" é per se inválido ou que o lançamento de moeda apenas teria sido uma abordagem inválida no caso em questão. Voltarei a esse assunto posteriormente $^{14}$ ).

Substancialmente, tribunais erram, às vezes, ao assumir que a incerteza exige uma fundamentação do pior caso. Isto é, cortes assumem que, sob incerteza, alguma versão do pior caso (maximin) ou (em geral)

NASDAQ-100, Standard \& Poor's 500 - S\&P 500 e Índice Bovespa - IBOVESPA), entre outras classes.

${ }^{11}$ [N.T.] Por meio de uma tradução livre, trata-se da Comissão de Seguros e Câmbio.

${ }_{12} \mathrm{Cf}$. American Equity Investment Life Insurance Co. Securities and Exchange Commission, 613 F. 3d 166 (2010).

${ }_{13}$ Para explanações mais amplas de temas semelhantes, além da matéria do Direito Administrativo, cf. DUXBURY, Neil. Random Justice: on Lotteries and Legal Decision-Making. Oxford: Oxford University Press, 2002; ELSTER, Jon. Solomonic Judgments: Studies in the Limitations of Rationality. Cambridge, MA: Cambridge University Press, 1989; e CALABRESI, Guido; BOBBITT, Philip. Tragic Choices. New York, NY: W.W. Norton \& Company, 1978.

${ }^{14}$ Cf. Judulang v. Holder, 132 S. Ct. 476, 485 (2012). 
premissas altamente conservadoras são o único curso racional. Ao contrário, diante da incerteza, um racional tomador de decisão pode alocar o valor- $\alpha$-o parâmetro que captura pessimismo ou otimismo - em qualquer lugar dentro de um intervalo definido pelo pior e pelo melhor dos cenários; os tribunais deveriam deferir às agências a escolha sobre quanto pessimista ser. Há um elemento inescapável de arbitrariedade na escolha de um parâmetro- $\alpha$ e, ainda assim, os tribunais não podem melhorar a situação demandando das agências razões que não podem ser fornecidas ou exigindo que as agências usem premissas maximamente pessimistas - um critério escolhido arbitrariamente por si só.

Há um papel próprio para cortes de assegurar que as agências tenham recursos adequadamente investidos na coleta de informações, o que pode resolver a incerteza, talvez a transformando em risco ou, até mesmo, em certeza. Não obstante, os problemas procedimentais e substanciais que identifiquei podem se desdobrar no nível mais elevado, pois, em alguns casos, o valor de investimentos adicionais em coleta de informações será, ele próprio, genuinamente incerto. Se assim for, os tribunais devem ter deferência às escolhas de segunda ordem das agências sobre investimentos informacionais pelos mesmos fundamentos que justificam a deferência às escolhas de primeira ordem sob incerteza feitas por agências.

\section{INCERTEZA, RACIONALIDADE E DIREITO}

Começarei expondo algumas noções jurídicas. No Direito Administrativo norte-americano, em nível federal, os requisitos de racionalidade administrativa derivam de várias fontes, principalmente da Cláusula de Devido Processo Legal da Quinta Emenda e da Administrative Procedure Act (APA).$^{15}$ Em muitos casos que discutirei adiante, a National Environmental Policy Act (NEPA) reforça indiretamente esses requisitos ao ordenar a consideração de valores ambientais que, por outro lado, poderiam ser excessivamente reduzidos. ${ }^{16} \mathrm{O}$ requisito de racionalidade do devido processo é mínimo e, no Direito Administrativo, tem sido amplamente suplantado pelos requisitos mais exigentes da APA

${ }^{15}$ Cf. Administrative Procedure Act (APA) [Lei do Processo Administrativo], 5 U.S.C. 500-559 (2006).

${ }^{16}$ Cf. National Environmental Policy Act (NEPA) [Lei da Política Nacional do MeioAmbiente], 42 U.S.C. 4321-47 (2006).

3 JOURNAL OF INSTITUTIONAL STUDIES 1 (2017) 
e de marcos legais como a NEPA. ${ }^{17}$

\section{Administrative Procedure Act}

Tal como é relevante aqui, a APA determina que as agências devem atuar dentro dos limites das competências legais que lhes foram delegadas, devem fornecer "provas substanciais" ou, pelo menos, um arcabouço probatório razoável para suas descobertas de fato e, mais importante para meus propósitos, devem expor motivações para suas escolhas políticas que conectem os fatos desvendados às escolhas feitas. A última exigência decorre, mais diretamente, da Seção 706(2)(A) da Lei, dispondo que Tribunais devem anular atos de agências que sejam "arbitrários, caprichosos, [ou] um abuso de poder". ${ }^{18}$ A obrigação resultante segue por muitos nomes - ambos os termos "revisão de arbitrariedade e capricho" e "revisão minuciosa" são populares em diferentes ramos do Direito Administrativo - mas vou usar o rótulo mais genérico, "revisão de racionalidade". Para explicar a interação entre revisão de racionalidade e incerteza, começarei enquadrando as questões legais.

Autorização Legal. A fim de isolar a questão da formulação racional de políticas, assumirei que a autoridade legal atribuída à agência lhe permite tomar uma série de decisões sob incerteza. Com base na estrutura normativa predominante, construída em duas famosas decisões do

17 No caso Motor Vehicle Manufacturers Association of the United States, Inc. v. State Farm Mutual Automobile Insurance Co., 463 U.S. 29, 43 n.9 (1983), a Corte observou que “a presunção de constitucionalidade proporcionada à legislação proposta pelo Congresso" é mais forte do que "a presunção de regularidade proporcionada à agência no exercício de suas competências legais".

18 [N.T.] O autor, ao citar situações que ensejam controle judicial de atos de agências, refere-se, genericamente, a certos vícios que desafiam a racionalidade exigida pela APA. Por essa razão, optou-se por traduzir o termo abuse of discretion como "abuso de poder", termo que, no Direito Administrativo brasileiro, admite espécies de vícios, como o "desvio de poder" (ou finalidade) e o "excesso de poder". Ressalte-se que este último não deve ser confundido com a referida "arbitrariedade". Neste trabalho, "arbítrio" pode representar uma estratégia perfeitamente racional para enfrentar a incerteza genuína, não correspondendo à prática de atos que excedem sua competência legal. "Arbitrariedade", na teoria da decisão racional sob incerteza, pode assumir acepção distinta daquela predominante na teoria do Direito e, em especial, no Direito Administrativo. 
Direito Administrativo, Chevron v. NRDC (1984) e United States v. Mead Corp. (2001), agências produzindo regras ou envolvidas em adjudicação formal costumam ser consideradas detentoras de discricionariedade sempre que as disposições relevantes forem omissas ou ambíguas - e, no Estado regulatório, essa é uma situação cotidiana. ${ }^{19}$

Por óbvio, não há exigência legal de que seja assim. Nas matérias em que a Constituição não se aplica, o Congresso pode especificar, exatamente, o que a agência deve ou não fazer em situação de incerteza. Leis podem exigir que agências usem premissas maximin em situação de incerteza, ou não. Elas podem impor que agências coletem certa quantidade de informação, ou não. Tudo depende do Congresso. Mas instruções desse tipo não são comuns no Direito Administrativo. $\mathrm{O}$ normal é que agências atuando sob incerteza possuem discricionariedade, porque as disposições legais pertinentes não especificam com clareza, de uma forma ou de outra, o que a agência deve, pode ou não pode fazer. E esse é o tipo de caso que presumo obter para os propósitos aqui discutidos.

Doutrina Atual. Supondo que a agência possui discricionariedade, o que exige a revisão da racionalidade em situação de incerteza genuína? A Direito não é claro, em parte, porque os tribunais são cronicamente obscuros quanto às diferenças entre risco, incerteza e ignorância e, consequentemente, usa uma terminologia vaga que confunde os assuntos. Em uma recente decisão, New York v. Nuclear Regulatory Commission (D.C. Cir., 2012), o Corte de Apelações do Circuito do Distrito de Columbia - o tribunal referência em Direito Administrativo nos Estados Unidos - foi tão longe quanto o uso descuidado da linguagem a ponto de sugerir que uma agência, ao avaliar as consequências ambientais de seus atos, deve articular uma análise prospectiva de danos que "examina, tanto a probabilidade de determinado dano ocorrer, quanto suas consequências caso ele, de fato, ocorra". ${ }^{20}$ Isso serviu para ignorar as incertezas genuínas espetacularmente exibidas no caso diante da corte. Estava em questão o problema de longo prazo de como descartar combustível nuclear gasto, uma substância que permanece potencialmente prejudicial, segundo a própria corte, por "intervalos de tempo, aparentemente, além da compreensão humana". ${ }^{21}$ Nenhum ator humano, a meu ver, tem qualquer justificativa epistêmica para atribuir probabilidades a eventos que podem ou não ocorrer daqui a eras. No

${ }^{19}$ Cf. Chevron U.S.A., Inc. v. Natural Resources Defense Council, Inc., 467 U.S. 837 (1984); e United States v. Mead Corp., 533 U.S. 218 (2001).

${ }^{20}$ Cf. New York v. Nuclear Regulatory Commission, 681 F. 3d 471, 482 (D.C., Cir. 2012).

${ }^{21}$ Cf. New York v. Nuclear Regulatory Commission, 681 F. 3d 474 (D.C., Cir. 2012). 
entanto, há provavelmente menos aqui do que se encontra na prática. Eu não acho que precisamos imputar ao Circuito do Distrito de Colúmbia algum tipo de visão Bayesiana de que a incerteza não existe ou não apresenta problemas característicos. Ao contrário, a compreensão judicial da distinção entre o risco e a incerteza knightiana é instável.

Um conjunto de princípios gerais e bem-definidos de Direito Administrativo é útil para estruturar a revisão da racionalidade em situações de incerteza. Um deles é que cortes revisoras devem ser o "mais deferente" possível quando agências fazem "previsões, dentro de [suas] área[s] de especial expertise, nas fronteiras da ciência". ${ }^{22}$ Outro princípio, aplicável quando há divergência entre especialistas, é que agências têm a prerrogativa de repousar sobre as opiniões razoáveis de seus qualificados peritos internos..$^{23}$ Como demonstrarei, tribunais violam esses princípios frequentemente, não que juízes deixem de entende-los como aplicáveis, mas porque os juízes cometem erros conceituais sobre o que conta como decisão racionalmente tomada sob incerteza.

Argumentarei, por exemplo, que a melhor leitura desses princípios abordados implica que cortes devem agir com deferência às agências em situações de incerteza bruta, em que fatos bem-definidos acerca do mundo e relevantes para a decisão não podem ser averiguados (a um custo aceitável); de incerteza estratégica, em que escolhas interdependentes criam equilíbrios múltiplos; e de incerteza de modelagem, em que o próprio quadro analítico a ser usado para avaliar as escolhas incertas não é claro. Além disso, os princípios implicam que

${ }_{22}$ Cf. Baltimore Gas \& Electric Co. v. Natural Resources Defense Council, 462 U.S. 87, 103 (1983). No contexto da regulação do arsênico e, mais geralmente, Sunstein argumenta que, às vezes, "agências devem decidir em meio a uma incerteza científica considerável e com base em juízos de valor sobre os quais pessoas razoáveis podem discordar. Se as agências fossem tanto abertas, quanto razoáveis, o papel judicial está no seu fim." SUNSTEIN, Cass. The Arithmetic of Arsenic. Georgetown Law Journal, Vol. 90, 7, 2002, p. 2.259. No entanto, Sunstein acrescenta que "[é] claro, cortes devem invalidar julgamentos arbitrários ou indefensáveis". SUNSTEIN, Cass. The Arithmetic of Arsenic. Georgetown Law Journal, Vol. 90, 7, 2002, p. 2259. Eu discordo em parte. Dados os dilemas da tomada de decisão sob incerteza, há circunstâncias sob as quais tribunais não devem invalidar nem mesmo os julgamentos de agências que são arbitrários, num sentido que definirei.

${ }^{23}$ Cf. Lands Council v. McNair, 537 F. 3d 981 (9th Cir., 2008); Marsh v. Oregon Natural Resources Council, 490 U.S. 360 (1989). Sobre as questões conceituais ao redor deste princípio, cf. VERMEULE, Adrian. The Parliament of the Experts. Duke Law Journal, Vol. 58, 8, 2009. 
agências não estão obrigadas a construir premissas precaucionárias ou de piores-cenários diante da incerteza, contrariamente a um meme que é surpreendentemente persistente em tribunais inferiores. Como mostrarei, a Suprema Corte, a seu crédito, rejeitou o meme em pelo menos duas ocasiões, em Baltimore Gas E Electric (1983) e Robertson v. Methow Valley Citizens Council (1989). ${ }^{24}$ Em todas essas situações, a lei deveria reservar espaço para decisões racionalmente arbitrárias - decisões estas a que nenhuma razão de primeira ordem pode ser oferecida, seja para um ou para outro sentido, dentro de certo domínio, ainda que há uma excelente razão para decidir nesse domínio.

\section{National Environment Policy Act}

A NEPA é um estatuto ambiental que perpassa todas as áreas do Direito Público. Sua exigência básica - uma obrigação mais procedimental do que substantiva - é que agências federais devem considerar se qualquer de suas ações terá efeitos significativos sobre o meio ambiente. Se a agência realiza uma avaliação ambiental e acredita que o ato não terá efeitos significativos, poderá confeccionar um relatório neste sentido. ${ }^{25}$ Os tribunais sustentarão este relatório contanto a agência tenha realizado uma análise rigorosa das questões e oferecido "razões convincentes" em seu suporte ${ }^{26}$, um padrão próximo a duplicar a

${ }^{24}$ Cf. Baltimore Gas \& Electric Co. v. Natural Resources Defense Council, 462 U.S. 87 (1983); e Robertson v. Methow Valley Citizens Council, 490 U.S. 332, 352 (1989).

${ }^{25}$ [N.T.] O autor emprega alguns termos específicos da legislação ambiental norteamericana nessa frase. A NEPA submete as agências a uma série de procedimentos para exercer suas atividades. Por isso, elas são obrigadas a, antes de implementar algumas decisões, realizar uma diligência intitulada Environmental Assessment (EA) [Avaliação Ambiental]. Dessa diligência, a agência estimará se haverá ou não impacto significativo no meio-ambiente. Cada situação enseja a confecção de um documento, contendo explicações técnicas acerca das premissas que conduziram àquele desfecho. O autor fez, acima, remição direta ao documento produzido quando a agência estimar não haver impacto significativo: o Finding of No Significant Impact (FONSI) [Relatório Negativo de Impacto Ambiental], que precisa ser motivado pela agência para eventual exercício da revisão de racionalidade pelas cortes federais. Adiante, o autor também se aborda o caso oposto, quando a agência estima impactos significativos e produz um Environmental Impact Statement (EIS) [Declaração de Impacto Ambiental].

${ }^{26}$ Cf. Foundation on Economic Trends v. Weinberger, 610 F. Supp. 829, 838 (D.C. Cir., 1985).

3 JOURNAL OF INSTITUTIONAL STUDIES 1 (2017) 
ordinária revisão de racionalidade da APA. Se a agência não puder cumprir esse teste, ela fica obrigada a fazer uma revisão mais extensa, chamada "declaração de impacto ambiental", que considera todos os riscos e danos ambientais potencialmente relevantes. ${ }^{27}$

Para meus propósitos aqui, a característica interessante deste enquadramento legal - a NEPA combinada com a APA - é que ele autoriza os tribunais a exigir de agências que invistam em coleta adicional de informações acerca de problemas ambientais. Na teoria da decisão racional, sob incerteza ou risco, uma questão é qual decisão seria racional diante de um conjunto determinado de informações; outra questão distinta, e logicamente anterior, é que quantidade de informação seria racional coletar antes de tomar uma decisão. Como mostrarei, a incerteza pode entrar em cena, tanto no primeiro nível (o que fazer), quanto no segundo nível (quanta informação coletar antes de decidir o que fazer).

No nível de controle judicial de atos de agências, surgem questões difíceis sobre quanta informação as cortes podem ou devem exigir que as agências coletem. Proponho que, de acordo com princípios do Direito Administrativo e princípios da NEPA corretamente entendidos, a existência de um problema incerto implica que, por vezes, saber se a coleta de informações suplementares justifica seus custos é per se incerto. Nesses casos, tribunais devem se abster para que agências tomem decisões racionalmente arbitrárias sobre quando interromper o processo de coleta de informações.

\section{QUANDO AS RAZÕES SE ESGOTAM}

Passo agora a analisar um tipo de erro que tribunais podem cometer quando agências enfrentam decisões sob incerteza genuína. Por enquanto, amparo-me na pergunta do se a situação é genuinamente de incerteza ou se, em vez disso, investimentos em coleta adicional de informações, cujos custos se justifiquem, poderiam solucionar a incerteza, transformando-a em risco ou certeza. Retomarei essa questão adiante. Por ora, presumo que a incerteza seja estipulada como genuína por todos os envolvidos, inclusive juízes revisores, e que toda informação justificada por seu custo já tenha sido coletada. Também presumo, por enquanto, que as agências estão agindo de boa-fé para maximizar o bem-estar em geral. Mais adiante, indagarei o que cortes devem fazer caso desconfiem

${ }^{27}$ Cf. Foundation on Economic Trends v. Weinberger, 610 F. Supp. 829, 838 (D.C. Cir., 1985). 
que agências invocam a incerteza como pretexto para proteger decisões tomadas sobre fundamentos ilegítimos.

Sustento que o erro em questão, em alguns casos, é a crença de ser sempre possível às agências conferir razões de primeira ordem a suas escolhas. Por uma razão de primeira ordem, refiro-me a uma razão que justifica a escolha da agência em relação a outras dentro de um conjunto viável. Uma razão de segunda ordem é uma razão para fazer uma escolha ou outra, dentro de um conjunto viável, mesmo que nenhuma razão de primeira ordem possa se dar. Em situações de incerteza, agências frequentemente terão razões de segunda ordem perfeitamente válidas, mesmo quando nenhuma razão de primeira ordem for possível. Em outras palavras, há um domínio de decisões das agências inevitavelmente arbitrárias em primeira ordem. Cortes revisoras não devem pressionar suas demandas por justificação e processos decisórios racionais além do ponto em que a possibilidade de razão se esgota.

\section{Incerteza bruta}

Um tipo de incerteza, a incerteza bruta, surge do simples custo de obter fatos acerca do mundo. ${ }^{28} \mathrm{O}$ lagarto-de-chifres de cauda achatada é uma "iguana pequena e enigmaticamente colorida... que é restrita a planícies e vales no lado oeste do deserto de Sonora".$^{29} \mathrm{O}$ secretário do interior tem a obrigação legal de decidir, à luz dos melhores dados científicos disponíveis, se deve incluir o lagarto na lista de espécies ameaçadas. Os detalhes são desnecessários, mas o estatuto constrange a prerrogativa do secretário de esperar até que sobrevenham informações; exige-se uma decisão imediata. ${ }^{30}$

Quantos lagartos-de-chifres de cauda achatada existem? Ninguém sabe e, até então, tal informação não pode ser obtida. Em litígio entre o

${ }^{28}$ Cf. ELSTER, Jon. Excessive Ambitions. Capitalism and Society, Vol. 4, 2, 2009.

${ }^{29}$ Cf. Tucson Herpetological Society v. Salazar, 566 F. 3d 873 (9th Cir., 2009), citando o Federal Register [Diário Oficial], Vol. 58, 227, 29 nov. 1993, p. 62.624-62.625.

${ }^{30}$ Deixo de lado a complicação técnica de que a agência, forçada a decidir, pode decidir que a listagem é "justificada, mas excluída" pois o risco para outras espécies tem maior prioridade. Cf. ALEXANDER, Kristina. Warranted but Precluded: What That Means under the Endangered Species Act (ESA). Congressional Research Service, CRS Report 7-5700, 2010. Trata-se apenas de um tipo de decisão, e é uma decisão que vai ao mérito da questão, constatando que a listagem é substancialmente justificada. Assim, uma decisão desse tipo não escapa, de modo algum, ao dilema que abordo. 
secretário do interior e grupos ambientalistas, "ambas as partes reconhecem que o tradicional método de 'contagem de dejetos' para estimar o tamanho da população de lagartos tem sido desacreditado" 31 , destruindo a base probatória das avaliações existentes. Por outro lado, um método mais recente, no qual os lagartos são capturados, marcados e, talvez, recapturados (com a taxa de recaptura de lagartos marcados transmitindo informações sobre o tamanho da população), ainda não forneceu informações confiáveis. O número de lagartos é um fato desconhecido que é sabidamente indecifrável, ao menos a curto prazo.

Como, então, deve o secretário decidir se alista o lagarto como uma espécie ameaçada? Como um tribunal revisor deve decidir se a decisão do secretário é arbitrária e caprichosa ou, ao invés disso, racional? Por conveniência, suponhamos que o secretário possa perceber que o número de lagartos é alto ou baixo. No caso real, o secretário efetivamente escolheu ser "alto". Ele reputou que as populações permaneceram viáveis com a quantidade existente de lagartos. A Corte de Apelações rejeitou essa conclusão, dispondo que "se a ciência sobre tamanho e tendências da população está subdesenvolvida e pouco clara, o Secretário não pode razoavelmente inferir que a ausência de evidência de declínio populacional equivale a evidência de persistência... Concluímos, portanto, que o registro administrativo não ampara a determinação do secretário de que as populações de lagartos persistem com a atual quantidade existente da espécie". ${ }^{32}$

O problema com a conclusão do tribunal é que o registro administrativo também não amparou a conclusão contrária. Uma decisão contrária do secretário, de que as populações não permaneceriam viáveis com a quantidade de lagartos, teria sido igualmente infundada. $\mathrm{O}$ juiz John Noonan, dissentindo, acertou. "É de adivinhar", escreveu ele, "se os lagartos estão se multiplicando ou declinando. Em um concurso de adivinhação, alguém poderia ter deferência para o árbitro do governo" ${ }^{33}$

Imaginando-se o ponto de vista do juiz Noonan, a agência foi apresentada com uma escolha pela qual havia razões de segunda ordem a fazer - de fato, uma obrigação de segunda ordem a fazer -, mas nenhuma razão de primeira ordem para escolher em um ou outro sentido. Digo uma escolha, e não uma descoberta, porque os fatos da matéria eram, para os atores envolvidos, epistemologicamente inalcançáveis. O secretário teve de decidir em que direção dar um salto de fé e é um tipo de hiperracionalismo patológico exigir que o secretário

${ }^{31}$ Cf. Tucson Herpetological Society v. Salazar, 566 F. 3d 873, 879 (9th Cir., 2009).

${ }^{32}$ Cf. Tucson Herpetological Society v. Salazar, 566 F. 3d 873, 877 (9th Cir., 2009).

${ }^{33}$ Cf. Tucson Herpetological Society v. Salazar, 566 F. 3d 873, 883 (9th Cir., 2009). 
justifique porque seguiu nessa direção ao invés de outra.

Uma reação natural em relação ao caso dos lagartos, e à incerteza em geral, é usar algum tipo de raciocínio padrão. ${ }^{34}$ Se não sabemos quantos lagartos existem, talvez devêssemos errar por cautela. O problema é que há muitas maneiras de interpretar essa injunção. $\mathrm{O}$ secretário pode decidir que o erro tipo I, alistar o lagarto como ameaçado quando na verdade não é, é menos custoso do que erro tipo II, deixar de alistá-lo como ameaçado quando realmente é, de modo que o cuidado requer uma estratégia agressiva de alistamento. Por outro lado, o secretário pode decidir que errar por cautela significa não alistar as espécies como ameaçadas se for extremamente plausível - como ninguém pode dizer que elas não o sejam. Existem várias posições padrão, substantivas e relevantes para o problema, que o secretário pode invocar.

Diante disso, o juiz Noonan sugere uma forma diferente de raciocínio padrão. Os ambientalistas recorrentes - os próprios demandantes - estão desafiando a conclusão do secretário. A APA é bastante clara ao dispor que recai sobre eles o ônus da prova para revelar que a decisão é arbitrária. $^{35}$ Se os fatos que permitiriam tal demonstração são inalcançáveis, então, o secretário ganha em virtude da disposição legal, mesmo que também não possa provar estar correto se as posições fossem trocadas. Um empate beneficia o árbitro do governo.

A visão que estou sugerindo admite, com otimismo, que a conclusão do secretário é arbitrária em primeira ordem. Mas esse é um ponto sobre arbitrariedade no sentido da teoria da decisão, não sobre arbitrariedade no sentido jurídico. Em termos legais, pretendo argumentar que decisões em que se esgotam as razões de primeira ordem não devem contar como arbitrárias nos termos da APA. Não é juridicamente arbitrário tomar uma decisão inevitável, apoiando-se em válidas razões de segunda ordem, mesmo que a decisão seja arbitrária em primeira ordem.

\section{Incerteza estratégica}

Permitam-me, agora, passar da incerteza bruta - sobre fatos epistemologicamente inatingíveis que, de certo modo, estão lá fora - para uma forma diferente de incerteza, decorrente da interdependência estratégica das escolhas de atores. Esse é um campo mais da teoria dos

${ }^{34} \mathrm{Cf}$. HALPERN, Joseph. Reasoning about Uncertainty. Cambridge, MA: MIT Press, 2005.

${ }^{35}$ Cf. Administrative Procedure Act (APA) [Lei do Processo Administrativo], 5 U.S.C. 556(d), 706(2)(E) (2006). 
jogos do que da teoria da decisão. A teoria dos jogos está cheia de equilíbrios múltiplos, especialmente, em jogos indefinidamente repetidos, mas também de modo geral. ${ }^{36}$ Alguns jogos não têm uma solução única em estratégias puras, de modo que as partes racionais tornarão seu comportamento, ao menos parcialmente, imprevisível. Outros jogos sequer possuem um solução única, mesmo com estratégias mistas. E os participantes do jogo podem ter experiência insuficiente com o comportamento de outros jogadores para formar crenças bemembasadas epistemologicamente acerca do que aqueles outros são capazes ou tendentes de fazer, o que dá origem a uma verdadeira incerteza estratégica.

A incerteza estratégica surge constantemente no âmbito do problema do contraterrorismo. No Tri-Valley Cares, o tribunal analisou se o Departamento de Energia deveria criar uma instalação de pesquisa de risco biológico nível 3 no Lawrence Livermore National Laboratory. ${ }^{37}$ Como as cortes de revisão deveriam ter avaliado a racionalidade da decisão do departamento? Um problema com a criação da instalação foi que patógenos poderiam escapar por acidente; outro foi que a instalação poderia se tornar alvo de um ataque terrorista. Havia uma quantidade razoável de experiência acumulada com tais instalações, em outros lugares, e um bom senso de como construir e operar tais instalações para minimizar a possibilidade de acidentes. Mas a instalação proposta para Lawrence Livermore tinha algumas características únicas. Ao tempo da construção, era a única instalação nível 3 a ocupar o mesmo complexo de um centro de pesquisa em armas nucleares ${ }^{38}$ e foi construída depois do 11 de Setembro, levantando difíceis questões sobre riscos de contraterrorismo, tanto de fontes domésticas, quanto internacionais.

O departamento decidiu a favor da construção da instalação. Os demandantes se opuseram à decisão com fundamento na NEPA e na APA, argumentando que o departamento não havia conferido a devida atenção aos riscos de terrorismo e aos danos resultantes para as pessoas e o meio-ambiente caso os patógenos escapassem. Ao fazer a sua avaliação, o departamento baseou-se em um modelo desenvolvido pelo Exército para mensurar os riscos de liberação de patógenos após um desastre natural ou acidente mecânico. $\mathrm{O}$ modelo sugeriu que os danos máximos cogitáveis de uma liberação eram modestos e que a chance de liberação, em primeiro lugar, embora impossível de quantificar, era

${ }^{36}$ Cf. FUDENBERG, Drew; MASKIN, Eric. The Folk Theorem in Repeated Games with Discounting or with Incomplete Information. Econometrica, Vol. 54, 3, 1986.

${ }^{37}$ Cf. Tri-Valley Cares v. U.S. Department of Energy, 671 F. 3d 1.113 (2012).

${ }^{38}$ Cf. Tri-Valley Cares v. U.S. Department of Energy, 671 F. 3d 1.113, 1.119 (2012). 
remota. Os peritos a favor dos demandantes alegavam, contudo, que esse modelo era inapropriado para o problema, que envolvia o risco de deliberados ataques de terroristas. A diferença entre riscos de desastre ou acidente, por um lado, e riscos de terrorismo, por outro, era, neste caso, também uma forma de incerteza de modelagem. A própria estrutura para avaliar o problema foi contestada pelas partes. ${ }^{39}$

A opinião dos demandantes pode estar correta ou não. A questão era genuinamente incerta, em parte, porque tinha uma dimensão estratégica. Os terroristas presumidamente seriam capazes de saber ou adivinhar algo sobre o modelo que o departamento estava usando. Afinal, a decisão do tribunal explicando os pontos controvertidos é uma questão de registro público. A consequência é que a escolha do modelo pelo próprio departamento afetaria, endogenamente, o risco a ser modelado - a fatia da incerteza estratégica. Supondo que o modelo mostrou que a possibilidade de um ataque terrorista era baixa, alguém poderia imaginar que o modelo se fragilizou porque seu uso sugeriu que o departamento foi complacente e, assim, ofereceu maiores incentivos a terroristas para se concentrarem em Lawrence Livermore em relação a outros potenciais alvos. Outros poderiam até imaginar que o modelo estava se fortalecendo, porque mostrou aos terroristas que o benefício esperado (de seu ponto de vista) de um ataque sobre a instalação era, de fato, baixo. Sem mais informações sobre uma provável resposta dos terroristas, algo que é essencialmente um jogo de adivinhação, é irredutivelmente obscuro se o modelo do departamento aumentou, reduziu ou não teve efeito sobre a chance de incidente terrorista na instalação. Em circunstâncias de incerteza estratégica, as razões se esgotam, dentro dos amplos limites estabelecidos pela autoridade legal da agência.

O tribunal confirmou a decisão do departamento de construir a instalação, principalmente, porque, se os especialistas discordarem do modelo apropriado a ser aplicado a um problema, a agência tem a prerrogativa de se basear no modelo preferido por seus próprios experts. ${ }^{40}$ Essa disposição era, na realidade, a mesma apresentada pelo juiz Noonan no caso dos lagartos, embora mais aplicada à incerteza estratégica do que à incerteza bruta. Devido à irredutível incerteza criada pela indeterminação estratégica, não há razão para favorecer um modelo ou outro, pelo menos dentro dos amplos limites da opinião profissionalmente respeitável.

Estou extrapolando ou enfeitando um pouco. A real opinião da corte meramente advertiu para a incerteza do modelo e para a divergência

${ }^{39}$ Cf. Tri-Valley Cares v. U.S. Department of Energy, 671 F. 3d 1.113, 1.125 (2012).

${ }^{40}$ Cf. Tri-Valley Cares v. U.S. Department of Energy, 671 F. 3d 1.113, 1.119 (9th Cir., 2012).

3 JOURNAL OF INSTITUTIONAL STUDIES 1 (2017) 
entre especialistas e, então, concedeu vitória à agência, sem explicar as profundas fontes da incerteza que causou a controvérsia. Seja qual for a adequação da explicação do tribunal, no entanto, creio que ele tinha as intuições corretas e atingiu o resultado devido. Saber se construir uma instalação de biossegurança em Lawrence Livermore era prudente é uma decisão na fronteira do concebível com o inconcebível, onde agências podem ou não dar um salto de fé, dependendo de quão intenso esteja seu apetite pelo risco. Uma vez alcançada essa fronteira, tribunais que exigem razões mais profundas estão pedindo o impossível.

\section{Reconhecendo que as razões se esgotam}

Finalmente, há a questão de como as cortes revisoras devem supostamente saber que elas (ou, mais precisamente, as agências) estão enfrentando tais decisões em que é racional ser arbitrário. Essas situações não vem rotuladas por Deus e, se as agências têm uma vantagem informacional relativa sobre as cortes de revisão, como esperar do tribunal a percepção logicamente antecedente de que surgiu um caso de decisão racionalmente arbitrária? ${ }^{41}$

Naturalmente, é impossível ter certeza, mas há uma série de abordagens práticas que as cortes de revisão podem usar. Em primeiro lugar, uma característica especial de problemas que demandam decisões racionalmente arbitrárias é uma espécie de reversibilidade da imagem espelhada. Se a agência escolhe $A$ em detrimento de $B$ e o tribunal anula essa decisão como arbitrária, também seria o caso de a escolha de $\mathrm{B}$ em detrimento de A pela agência ser anulada, exatamente pelos mesmos fundamentos. $\mathrm{Na}$ verdade, qualquer escolha feita pela agência poderia ser revertida por falta de razões de primeira ordem. Reconhecendo isso, a corte de revisão deve perceber que a agência pode estar enfrentando uma situação em que nenhuma escolha não-arbitrária seja viável.

${ }^{41}$ É tentador chamar isso de "passo zero" para decisões racionalmente arbitrárias, em analogia à inspeção sobre se o precedente Chevron se aplica. Cf. SUNSTEIN, Cass. Chevron Step Zero. Virginia Law Review, Vol. 92, 2, 2006. Tentador, mas creio que seja incorreto. O passo zero de Chevron é um "seletor" entre dois distintos padrões decisórios e determina qual deles prevalece. Aqui, ao contrário, o padrão de revisão nunca muda; é sempre revisão por "arbitrariedade e capricho" com base na seção 706(2) da APA. A tarefa da corte de revisão é apenas entender o tipo de problema enfrentado pela agência para que o padrão arbitrário e caprichoso possa ser aplicado de maneira sensata. 
Um exemplo pode ser esboçado a partir do caso das anuidades fixas indexadas. Conforme descrito acima, a SEC tinha de decidir se tais instrumentos deveriam contar como anuidades nos termos da legislação federal de valores mobiliários e era legalmente obrigada a considerar os efeitos de sua decisão sobre a concorrência e a eficiência. ${ }^{42}$ Para os presentes propósitos, suponhamos que a SEC acreditasse racionalmente que uma decisão, em qualquer sentido, promoveria a concorrência e a eficiência ao reduzir a insegurança jurídica para empresas sujeitas à regulação. Qualquer decisão substantiva seria melhor. Uma decisão em qualquer sentido seria melhor do que uma confusão em curso. No entanto, era também irredutivelmente incerto qual decisão de primeira ordem seria a melhor para promover a concorrência e a eficiência.

Em tal situação, independentemente da escolha da SEC se as anuidades fixas indexadas contariam ou não como anuidades, ela estava obrigada a decidir de uma forma ou de outra. No entanto, o problema era que uma corte revisora poderia anular ambas as decisões, alegando que reduzir insegurança jurídica não seria uma razão suficiente para explicar porque a SEC preferiu escolheu um caminho em relação ao outro. Afinal de contas (segundo um raciocínio falacioso), a SEC também poderia ter reduzido a insegurança jurídica tomando a outra decisão. ${ }^{43} \mathrm{~A}$ falha do tribunal em reconhecer que o problema estava sujeito à reversibilidade da imagem espelhada assegurou o pior resultado possível ao perpetuar a insegurança jurídica.

Uma segunda abordagem prática é que problemas que demandam decisões racionalmente arbitrárias produzirão, com frequência, discordâncias intratáveis entre os especialistas ${ }^{44}$, como no caso da instalação de biossegurança em Lawrence Livermore. Certamente, será necessária a experiência para alcançar a fronteira da incerteza em que estão as decisões racionalmente arbitrárias, mas a expertise será finalmente incapaz de prescrever uma escolha única entre as opções viáveis. Isso dificilmente é uma inferência inequívoca, porque o desacordo entre os especialistas pode surgir por outras razões também, mas a existência de tal desacordo é uma evidência positiva de que a fronteira de incerteza foi atingida.

Finalmente, o tribunal pode até pedir à agência uma declaração direta de que surgiu um problema que demanda decisões racionalmente

${ }^{42}$ Cf. American Equity Investment Life Insurance Co. v. SEC, 613 F. 3d 166 (2010).

${ }^{43}$ Cf. American Equity Investment Life Insurance Co. v. SEC, 613 F. 3d 166, 177-178 (2010).

${ }^{44}$ Al-Najjar faz um apontamento análogo a partir de uma perspectiva bayesiana. Cf. AL-NAJJAR, Nabil I. A Bayesian Framework for the Precautionary Principle. Journal of Legal Studies, Vol. 44, S-2, 2015.

3 JOURNAL OF INSTITUTIONAL STUDIES 1 (2017) 
arbitrárias. A possibilidade de a agência alegar falsamente, ou como pretexto, que um caso dessa ordem surgiu é real - tratarei dessas questões adiante -, mas a declaração direta servirá como um tipo de vínculo reputacional. Agências em uma recorrente relação com cortes de revisão serão relutantes em assumir o risco de fazer uma falsa alegação que poderá ser exposta posteriormente.

\section{OTIMISMO, PESSIMISMO E INCERTEZA}

Passo agora a um problema relacionado - um caso específico particularmente importante de razões que se esgotam. Sob genuína incerteza, que premissas tomadores de decisão devem usar? Em particular, quão otimistas ou pessimistas eles devem ser? Existe um influente meme popular no sentido de que, sob incerteza, as premissas do pior caso possível têm certa prioridade. "Errar por cautela". "Melhor prevenir do que remediar". Os provérbios são muitos.

Um dos problemas é que o conselho de errar por cautela será, por vezes ou frequentemente, indeterminado. $\mathrm{O}$ "Teorema Sombrio" 45 mostra que, dadas certas suposições sobre a distribuição dos riscos de mudanças climáticas - a existência de uma fat-tail -, danos catastróficos de magnitude espantosa são uma possibilidade real e devem suplantar outras considerações, predominando na decisão do problema. ${ }^{46}$ Mas isso

${ }^{45}$ Cf. WEITZMAN, Martin. On Modeling and Interpreting the Economics of Catastrophic Climate Change. Review of Economics and Statistics, Vol. 91, 1, 2009.

${ }^{46}$ [N.T.] O autor aborda dois termos presentes nas ciências econômica e estatísticas que podem ser esclarecidos: fat-tail e Teorema Sombrio. Muitas análises de risco calculam a probabilidade de determinados acontecimentos por sua distribuição. Nos gráficos dessa distribuição, há curvas de probabilidade - chamadas curtoses - que podem ser classificadas de três formas. A curva mais frequente é a mesocúrtica, que, com formato de um sino, exibe a conhecida distribuição normal das probabilidades. Significa que, em determinadas áreas do gráfico, a probabilidade pode ser alta. Quando esse "sino" se reveste de contornos altos e finos, a curtose se classifica como leptocúrtica. Essa curva é usualmente referida, na estatística e na economia, como "cauda fina" (thin-tail) e mostra que a probabilidade de ocorrência do fato analisado é muito elevada, porém, em um ponto bem específico, tornando-se pouco provável no restante do gráfico. Por fim, existe a curva platicúrtica. Economistas e estatísticos costumam chamá-la de "cauda gorda" (fat-tail), pois, em nenhum momento do gráfico, a probabilidade atinge um nível elevado. Isso significa que o fato estudado é muito pouco provável de ocorrer sob quaisquer circunstâncias. Justamente por essa razão, economistas costumam 
não significa, necessariamente, que devemos reduzir a atividade econômica imediatamente, apostando na prevenção de mudanças climáticas catastróficas. Pode haver, igualmente, um teorema sombrio sobre os riscos fat-tail catastróficos de se fazer isso. ${ }^{47}$ Talvez a consequente retração da economia possa se tornar tão severa que cause conflitos globais que reduzam radicalmente os padrões de vida ou até mesmo aniquilem a população humana. O exemplo generaliza. Uma dificuldade crônica com as estratégias maximin para lidar com a incerteza é que os cenários de pior caso, geralmente, estão em todos os lados do problema. Onde isso é verdade, a ideia de tomar precauções pode ser indeterminada. ${ }^{48}$

No entanto, há também um segundo problema, analiticamente distinto. Mesmo quando uma abordagem precaucionária é conceitualmente determinada, não significa que, sob incerteza, só premissas pessimistas ao extremo sejam racionais. No modelo estrutural Arrow-Hurwicz ${ }^{49}$, a tomada de decisão racional sob incerteza pode se basear no pior caso, no melhor caso ou em uma moderada combinação

negligenciar riscos avaliados como fat-tail, por se tratar de eventos extremamente improváveis de acontecer e que podem exigir medidas de elevado custo para prevenção, e recomendam políticos a não se preocuparem muito com problemas dessa ordem. Todavia, Martin Weitzman é um pesquisador engajado no tema da economia das mudanças climáticas que aborda fenômenos catastróficos de extremo impacto, embora altamente improváveis de acontecer (fat-tails). Devido aos danos inestimáveis que esses acontecimentos improváveis podem causar, Weitzman sugere que se dê maior atenção a esses problemas, baseado em premissas como o valor da vida humana, a incerteza ilimitada quanto aos efeitos de tais eventos extremos e os limites de sobrevivência da civilização humana ou da vida como conhecemos. A fim de reforçar esse argumento, Weitzman constrói um modelo matemático para esclarecer os resultados da combinação dessas premissas, chamado Dismal Theorem, que acaba por exercer papel muito próximo de um princípio geral precaucionário na economia das mudanças climáticas.

${ }^{47}$ Cf. YOHE, Gary; TOL, Richard. Precaution and a Dismal Theorem: Implications for Climate Policy and Climate Research. Working Paper FNU, No. 145, 2007.

${ }^{48}$ Cf. SUNSTEIN, Cass. Worst-Case Scenarios. Cambridge, MA: Harvard University Press, 2007; e SUNSTEIN, Cass. Risk and Reason: Safety, Law, and the Environment. Cambridge, MA: Cambridge University Press, 2002.

${ }^{49}$ Cf. ARROW, Kenneth; HURWICZ, Leonid. An Optimality Criterion for DecisionMaking under Ignorance. In: C.F. Carter; J.L. Ford (eds.). Uncertainty and Expectations in Economics: Essays in Honour of G.L.S. Shackle. Oxford: Oxford University Press, 1972. 
dos dois extremos. ${ }^{50} \mathrm{O}$ maximin, que procura escolher o resultado com o melhor benefício no pior cenário, não é a abordagem exclusivamente racional. Igualmente racional é o maximax, que tenta escolher o resultado com o melhor benefício no melhor cenário. ${ }^{51}$ Uma generalização comum de Arrow-Hurwicz, a estrutura $\alpha$-maximin, conduz tomadores de decisão a escolher um parâmetro que pode variar de pessimismo máximo a otimismo máximo..$^{52}$ Não há base na teoria da decisões para que tribunais destaquem uma extremidade neste espectro - a extremidade do máximo pessimismo - e o elevem a uma espécie de exigência universal de contingência para situações de incerteza. ${ }^{53}$

${ }^{50}$ Cf. WOODWARD, Richard; BISHOP, Richard. How to Decide When Experts Disagree: Uncertainty-Based Choice Rules in Environmental Policy. Land Economics, Vol. 73, 4, 1997.

${ }^{51}$ KELSEY, David; QUIGGIN, John. Theories of Choice under Ignorance and Uncertainty. Journal of Economic Surveys, Vol. 6, 2, 1992, p. 136-137.

52 Para uma revisão da literatura, com aplicações legais e regulatórias, cf. FARBER, Daniel. Uncertainty. Georgetown Law Journal, Vol. 99, 4, 2011.

${ }^{53}$ Aqui estou em terreno traiçoeiro, aventurando-me além de minha área de competência. No entanto, não parece que exista uma conexão intrínseca entre incerteza e pessimismo. Em modelos com priores não-únicos, o critério maxmin de Gilboa e Schmeidler aproxima-se da equivalência com maximin à medida que a gama de distribuições de probabilidade admissíveis cresce. Cf. GILBOA, Itzhak; SCHMEIDLER, David. Maxmin Expected Utility with a Non-Unique Prior. Journal of Mathematical Economics, Vol. 18, 2, 1989. O critério maxmin, entretanto, é derivado de um axioma de aversão à incerteza. GILBOA, Itzhak; SCHMEIDLER, David. Maxmin Expected Utility with a Non-Unique Prior. Journal of Mathematical Economics, Vol. 18, 2, 1989, p. 144. O axioma em si não é um requisito da racionalidade, e outros axiomas podem ser usados em seu lugar. Um ponto semelhante vale para a literatura sobre otimização robusta, que tende a usar o critério maximin de Wald como uma premissa padrão. Cf. WALD, Abraham. Statistical Decision Functions Which Minimize the Maximum Risk. Annals of Mathematics, Vol. 46, 2, 1945. O extremo conservadorismo do maximin de Wald cria um "preço de robustez", o que significa que outras premissas são igualmente respeitáveis. Cf. BERTSIMAS, Dimitris; SIM, Melvyn. The Price of Robustness. Operations Research, Vol. 52, 1, 2004. O mesmo vale para modelos de incerteza parcial, nos quais o tomador de decisões é capaz de construir uma classificação ordinal de probabilidade de possíveis estados. O comportamento otimista, ou do tipo maximax, é tão admissível quanto o comportamento pessimista, ou de tipo maximin. KELSEY, David. Choice under Partial Uncertainty. International Economic Review, Vol. 34, 2, 1993, p. 301-302. Em geral, há uma tendência flutuante na literatura de dizer que regras de decisão pessimistas, como o maximin, têm algum 
Há uma base geral, no Direito, para exigir uma contingência dessas? Legislações especiais podem, é claro, impor cautela em contextos específicos, mas será que o Direito Administrativo, de modo geral, exige de tribunais que apliquem premissas conservadoras sobre agências? Em 1978, o Council on Environmental Quality (CEQ), um órgão executivo encarregado de editar regulamentações para executar a NEPA, especificamente exigiu das agências uma abordagem do pior cenário possível em suas Environmental Impact Statements (EIS), se as informações relevantes sobre possíveis danos ambientais fossem inexistentes ou demasiadamente dispendiosas de se obter. ${ }^{54}$ A consequência foi que agências estavam obrigadas, ou se sentiam obrigadas, a abordar um conjunto de cenários altamente especulativos e implausíveis. ${ }^{55}$ Em 1986, o conselho revogou sua exigência de piores cenários e a substituiu. "A regulação, agora, exige de agências que obtenham informações incompletas ou indisponíveis em uma EIS, quando as obter não implique um custo exorbitante e for 'relevante para impactos significativos adversos razoavelmente previsíveis.' Se a informação não puder ser obtida por ser muito custosa ou porque os meios para obtê-las são desconhecidos, então, os regulamentos da CEQ exigem da agência que declare esse fato, juntamente de um resumo da relevância da informação e um resumo das provas confiáveis existentes no assunto". ${ }^{56}$ A Suprema Corte confirmou essa mudança em Methow Valley (1989), observando que a exigência do pior caso ameaçou "[distorcer] o processo de tomada de decisão ao superestimar danos altamente especulativos", desviando, assim, o limitado tempo das agências e seus recursos cognitivos acerca dos riscos ambientais mais significativos. ${ }^{57}$

Concluo que nem o Direito, nem os cânones da racionalidade exigem,

tipo de prioridade intuitiva - uma interrupção de diálogo para aqueles que não compartilham tal intuição, pelo menos de forma sistemática e transversal. KELSEY, David; QUIGGIN, John. Theories of Choice under Ignorance and Uncertainty. Journal of Economic Surveys, Vol. 6, 2, 1992, p. 137.

${ }^{54}$ [N.T.] Por uma tradução livre, trata-se do Conselho de Qualidade Ambiental. Cf. Federal Register [Diário Oficial], Vol. 43, 55.741, 29 nov. 1978, p. 55.978-55.984; e MATTIX, Carla; BECKER, Kathleen. Scientific Uncertainty under the National Environmental Policy Act. Administrative Law Review, Vol. 54, 3, 2002. Quanto à Environmental Impact Statement (EIS), cf. nota no 26 acima.

${ }^{55}$ Cf. MATTIX, Carla; BECKER, Kathleen. Scientific Uncertainty under the National Environmental Policy Act. Administrative Law Review, Vol. 54, 3, 2002.

${ }^{56}$ Cf. MATTIX, Carla; BECKER, Kathleen. Scientific Uncertainty under the National Environmental Policy Act. Administrative Law Review, Vol. 54, 3, 2002, p. 1.133.

${ }^{57}$ Cf. Robertson v. Methow Valley Citizens Council, 490 U.S. 332, 356 (1989). 
como regra, que agências escolham premissas seguras e cautelosas quando em situação de incerteza e que, em alguns casos, a própria ideia de usar premissas cautelosas é indeterminada de qualquer modo - por exemplo, onde existem riscos fat-tail em ambos os pratos da balança. Por isso, não há base para que os Tribunais imponham uma exigência de conservadorismo às agências através da implementação judicial da revisão da racionalidade sob a APA, ou mesmo sob a NEPA. No entanto, tribunais inferiores, às vezes, parecem restringir quando as agências fazem qualquer coisa que não seja suposições pessimista em situação de incerteza, apesar da advertência feita pela Suprema Corte no caso Methow Valley. Vou me confinar a um recente exemplo, entre muitos que decoram as páginas dos relatórios jurídicos.

O exemplo também vem do Direito das espécies ameaçadas. Os ursospardos de Yellowstone foram alistados como uma espécie ameaçada, em 1975, mas seus números aumentaram desde então a ponto de o Fish and Wildlife Service tentar retirá-los da lista. ${ }^{58} \mathrm{Na}$ decisão de revogação do alistamento, uma questão-chave era se os ursos estariam ameaçados pelo declínio na predominância do pinheiro-branco, uma árvore que lhes fornece uma importante fonte de alimento. Todas as partes reconheceram o potencial para tal ameaça, em parte por causa das mudanças climáticas, que tem estimulado o crescimento de parasitas e doenças que matam o pinheiro-branco, e em parte devido a uma correlação bem documentada entre as reduções do pinheiro-branco e a mortalidade do urso-pardo. ${ }^{59}$ Mas a agência amortizou a severidade da ameaça geral a ursos-pardos por vários motivos: os ursos-pardos são, notoriamente, flexíveis e adaptáveis com relação a suas fontes de alimento (se faltarem pinheirosbrancos, mais cestas de piquenique serão "roubadas"); o pinheiro-branco sempre foi um recurso altamente variável, que os ursos têm provado poder viver sem; e outras populações de ursos-pardos surgiram, apesar da perda de pinheiro-branco..$^{60}$ No geral, concluiu a agência, "a quantidade específica de declínio na distribuição do pinheiro-branco e a proporção desse declínio são difíceis de prever com certeza. A resposta específica dos ursos pardos ao declínio da produção de cones de pinheirobranco é ainda mais incerta" ${ }^{61}$

O tribunal, no entanto, declarou a posição da agência arbitrária,

${ }^{58}$ Cf. Greater Yellowstone Coalition, Inc. v. Servheen, 665 F. 3d 1.015, 1.019 (9th Cir., 2011).

${ }^{59}$ Cf. Greater Yellowstone Coalition, Inc. v. Servheen, 665 F. 3d 1.015, 1.025 (9th Cir., 2011).

${ }^{60}$ Cf. Greater Yellowstone Coalition, Inc. v. Servheen, 665 F. 3d 1.015, 1.027 (9th Cir., 2011).

${ }^{61}$ Cf. Greater Yellowstone Coalition, Inc. v. Servheen, 665 F. 3d 1.015, 1.028 (9th Cir., 2011), citando-se, Federal Register [Diário Oficial], Vol. 72, 60, 29 mar. 2007, p. 14.866-14.929. 
citando o caso de lagartos discutido anteriormente. ${ }^{62}$ "Pode ser que cientistas compilem dados demonstrando estabilidade da população de ursos pardos em face a declínios do pinheiro-branco. Essas informações, porém, simplesmente não estão nos registros diante de nós. A falta de qualquer dado mostrando um declínio populacional devido à redução do pinheiro-branco não é suficiente" ${ }^{\prime 63}$ Mas é claro que o ponto principal era que não havia, de qualquer forma, nenhuma informação no registro e (estou assumindo por agora) não havia qualquer procedimento para obter essa informação cujos custos se justificassem. A fundamentação da corte, na verdade, exigia da agência uma premissa conservadora ou pessimista acerca das consequências sabidamente incertas das reduções de pinheiro-branco, enquanto a agência havia escolhido uma premissa otimista. O primeiro não tem nenhuma prioridade analítica ou legal sobre o segundo; logo, o tribunal deveria ter mantido a decisão da agência.

Isso, certamente, é um jogo justo para formuladores de políticas criticarem as agências por um otimismo ou um pessimismo excessivo nesse assunto. Os instituidores de políticas, como o Presidente e os legisladores, têm a prerrogativa de definir $\alpha$-parâmetros como entenderem se encaixar em domínios específicos, por meio de decisões executivas ou da legislação. A legislação pode ordenar, embora raramente o faça, que agências tomem premissas substancialmente cautelosas diante da incerteza. ${ }^{64}$ Procedimentalmente, mencionei regulamentos prévios da NEPA, que exigiram de agências analisar os piores cenários possíveis. ${ }^{65}$ Mas nada disso implica que, pela atual legislação, tribunais tenham qualquer base para ler uma exigência de fato da tomada de decisão maximin dentro dos requisitos gerais de racionalidade do Direito Administrativo. Não há nenhuma razão sistemática para pensar que tribunais estejam melhor posicionados do que agências para definir $\alpha$-parâmetros e nenhuma razão geral para pensar que agências funcionarão mal ao fazê-lo de modo que tribunais sejam capazes de supervisionar ou corrigir. No sentido da teoria da decisão, a racionalidade não exige pessimismo; nem deveria fazê-lo no sentido jurídico.

Parte da intuição judicial, raramente articulada, deve ser que a escolha

${ }^{62}$ Cf. Greater Yellowstone Coalition, Inc. v. Servheen, 665 F.3d 1.030 (9th Cir., 2011), citando Tucson Herpetological Society v. Salazar, 566 F. 3d 870, 879 (9th Cir., 2009).

${ }^{63}$ Cf. Greater Yellowstone Coalition, Inc. v. Servheen, 665 F.3d 1.030 (9th Cir., 2011). ${ }^{64}$ A Clean Air Act, por exemplo, impõe a consideração de liberações acidentais de ácido fluorídrico causadas pelo pior caso. Cf. Clean Air Act (CAA) [Lei do Ar Limpo], 42 U.S.C. 7412(n)(6) (2006).

${ }^{65}$ Cf. Federal Register [Diário Oficial], Vol. 43, 55.741, 29 nov. 1978, p. 55.978-55.984. 
de um $\alpha$-parâmetro parece ser essencialmente arbitrário. Por que a agência deve definir o parâmetro aqui, e não lá, sem explicação? Ainda assim, isso não explica porque os tribunais parecem gravitar em direção ao maximin, em oposição ao maximax ou a quaisquer outras regras decisórias compatíveis com o modelo Arrow-Hurwicz. Esse tipo de comportamento judicial parece ocorrer porque o maximin ressoa como uma sabedoria popular pessimista ("melhor prevenir do que remediar") $\mathrm{e}$, portanto, fornece um critério emblemático aparentemente neutro e prudente. Mas isso não é neutro, nem é, necessariamente, mais prudente do que as alternativas. Afinal, também há sabedoria popular sobre o valor do otimismo ("quem não arrisca não petisca").

A agência também não deve ser encarregada de explicar o inexplicável. É tentador dizer que a obrigação mínima da agência é dar razões por ter definido o $\alpha$-parâmetro aqui ao invés de lá. Mas, na tomada de decisão sob incerteza genuína, agências operam nas fronteiras da razão. As agências, não menos que corporações ou empreendedores, agirão de forma mais ou menos corajosa, dependendo do que Keynes chamou de "espíritos animais". ${ }^{66}$ Com o passar do tempo, a opinião pública e os agentes produtores de políticas julgarão se as agências agiram com excessivo otimismo ou pessimismo. Enquanto isso, tribunais devem deixar a agência decidir.

Se essa postura de abnegação e tolerância judicial em relação à arbitrariedade racional parece implausível, até mesmo inatingível, a própria Suprema Corte nos deu um louvável contraexemplo. Em uma decisão de 1983, Baltimore Gas \& Electric v. Natural Resources Defense Council (1983), a questão era se a Nuclear Regulatory Commission poderia permitir que usinas nucleares fossem licenciadas sob a premissa otimista de que haveria liberação zero de combustível nuclear gasto a partir de seus reservatórios internos. ${ }^{67}$ Apesar da incerteza radical que envolve os efeitos de longo prazo do armazenamento de combustível nuclear ao meio-ambiente e à saúde, o tribunal afirmou, enfaticamente, que cabia à comissão fazer esse tipo de julgamento político incorporado na premissa liberação-zero e que não havia nada arbitrário ou irracional na abordagem da Comissão. ${ }^{68}$ Há formas variadas para confinar ou

${ }^{66}$ Cf. KEYNES, John Maynard. The General Theory of Employment, Interest and Money. New York, NY: Harcourt, Brace, 1936, p. 161.

${ }^{67}$ Cf. Baltimore Gas \& Electric Co. v. Natural Resources Defense Council, Inc., 462 U.S. 87 (1983).

${ }^{68}$ Cf. Baltimore Gas \& Electric Co. v. Natural Resources Defense Council, Inc., 462 U.S. 87, 105 (1983). 
restringir a fundamentação da Corte ${ }^{69}$, mas o espírito da decisão é suficientemente claro: juízes são perfeitamente capazes de reconhecer que, sob incerteza, o pessimismo não tem prioridade racional ou legal, assumindo, como sempre, que legislações pertinentes são silenciosas ou ambíguas.

\section{COLETA ÓTIMA DE INFORMAÇÕES}

Até agora tenho agrupado questões sobre a coleta de informações. Essas questões, sem dúvida, estão no cerne da NEPA, assim como da APA, na medida em que essas leis exigem de agências que sigam procedimentos racionais para coleta de informações, ambas em relação a efeitos ambientais e mais genericamente. Mas o que isso significa exatamente? Sob a incerteza, a que se assemelha a coleta ótima de informações?

Uma linha padrão na economia da informação é que tomadores de decisão devem investir na coleta de informações somente até o ponto em que os (crescentes) custos marginais de fazê-la se equiparem aos benefícios marginais esperados das informações adicionais. ${ }^{70}$ Se não houver custo para reverter uma decisão uma vez tomada, então, não há necessidade de esperar. Qualquer decisão atual pode ser desfeita se informações posteriores sugerirem que a agência errou. Porém, se houver algum custo positivo para reverter as decisões já tomadas, logo, esperar por novas informações tem um valor de opção que aumenta com o custo da reversão. ${ }^{71}$ Quanto maior o valor de opção, maior será o benefício de uma maior coleta de informações antes que a agência decida.

Essa abordagem pode ser adequada para ambientes estáveis, familiares e relativamente simples. Em ambientes desse tipo, tomadores de decisão podem formar distribuições de probabilidade epistemologicamente justificadas sobre o valor (esperado) de

${ }^{69}$ Por exemplo, a Corte observou que a premissa otimista estava embutida num conjunto de pressupostos que eram conservadores, em geral, e que o primeiro era, em parte, destinado a compensar o último. Cf Baltimore Gas \& Electric Co. v. Natural Resources Defense Council, Inc., 462 U.S. 94, 105 (1983). Isso, no entanto, também nega que o pessimismo tenha qualquer status predominante.

${ }^{70}$ Cf. STIGLER, George. The Economics of Information. Journal of Political Economy, Vol. 69, 3, 1961.

${ }^{71}$ Cf. DIXIT, Avinash; PINDYCK, Robert. Investment under Uncertainty. Princeton, NJ: Princeton University Press, 1994. 
informações futuras. Procurando bens de consumo, em um shopping, tenho uma ideia clara do valor esperado da informação que levantarei indo a mais uma loja. Contudo, muitos dos problemas enfrentados pelas agências não são assim. Onde o ambiente é tão inexplorado, ou tão complexo, que o benefício marginal da aquisição de informações adicionais é, em si mesmo, genuinamente incerto, pode haver custos proibitivos para colher a informação necessária para formar uma distribuição de probabilidade epistemologicamente justificada acerca do valor da informação..$^{72}$ Uma regressão infinita se aproxima: o tomador de decisão deve decidir o quanto investir na coleta de informações sobre o benefício marginal da coleta adicional de informações, e assim por diante. ${ }^{73}$

Como em corporações em mercados competitivos, tem sido observado que a "própria escolha de uma estrutura informacional maximizadora de lucros requer informação e não é aparente como o pretendente à maximização do lucro adquire essa informação, ou o que lhe garante não pagar um preço excessivo por isso". ${ }^{74} \mathrm{O}$ mesmo ponto se sustenta, com as modificações apropriadas, para agências que maximizam o bem-estar social. A incerteza pode afligir não apenas a decisão de primeira ordem da agência, mas também suas decisões de segunda ordem acerca de quanta informação coletar. ${ }^{75}$ Criticamente, não há qualquer solução não-arbitrária para essa regressão infinita. Isso é um tipo especial de problema de busca ótima, em que qualquer regra de parada é arbitrária dentro dos limites da incerteza relevante. ${ }^{76}$ Nas fronteiras do conhecimento, o que agências fazem é "como entrar em uma grande floresta para pegar cogumelos. Pode-se explorar as possibilidades em uma determinada região limitada, mas, em algum ponto, devem-se parar as explorações e começar a colheita, porque explorações adicionais em busca da possibilidade de encontrar mais e melhores cogumelos ao andar um pouco mais longe derrotaria o propósito da caminhada. Devese decidir parar as explorações em uma base intuitiva, isto é, sem

${ }^{72}$ Cf. ELSTER, Jon. Excessive Ambitions. Capitalism and Society, Vol. 4, 2, 2009.

${ }^{73}$ Cf. MELBERG, Hans. A Critical Discussion of Jon Elster's Arguments about Rational Choice, Infinite Regress and the Collection of Information. Unpublished thesis.

University of Oslo, Department of Economics, Oslo, 1999.

${ }^{74}$ Cf. WINTER, JR., Sidney. Economic "Natural Selection" and the Theory of the Firm.

Yale Economic Essays, Vol. 4, 1, 1964, p. 262.

${ }^{75}$ Cf. SUNSTEIN, Cass; ULLMANN-MARGALIT, Edna. Second-Order Decisions.

Ethics, Vol. 110, 1, 1999.

${ }^{76}$ Cf. WIENER, Jonathan Baert. Managing the Iatrogenic Risks of Risk Management.

Risk: Health, Safety and Environment, Vol. 9, 1, 1998. 
realmente investigar se explorações adicionais produziriam melhores resultados". ${ }^{77}$

O papel dos tribunais na revisão de racionalidade da coleta de informações de uma agência deve ser sensível a estas considerações. ${ }^{78}$ Nos casos ordinários da NEPA, por exemplo, cortes podem ser capazes de identificar casos em que as agências deixaram de fazer investimentos em coleta de informações cujos custos se justifiquem (darei um exemplo resumidamente). "Ordinário" significa que agências e tribunais tomaram decisões sobre problemas semelhantes, em ambientes semelhantes, com frequência suficiente para calcular o valor esperado de incrementos adicionais de informação. Todavia, em ambientes decisórios como os mencionados anteriormente - contraterrorismo, combustíveis nucleares, problemas de espécies ameaçadas de extinção na fronteira da compreensão biológica e ecológica -, tribunais deveriam conter suas mãos. Agências precisam ter margem de manobra para parar de coletar informações em um determinado ponto, inclusive e principalmente quando a localização desse ponto não puder ser justificada por motivos que pareçam racionais em um sentido de primeira ordem. Em ambientes informacionalmente incertos, "em algum ponto, o indivíduo deve asseverar de algum modo não calculado como ele usará recursos para estabilizar o que ele pretende: ele deve, na verdade, dar um tiro no escuro". ${ }^{79}$

No caso dos ursos pardos de Yellowstone, descritos anteriormente, o tribunal parece ter concebido indevidamente seu papel, ao exigir, na realidade, que a agência justificasse a escolha de uma regra de parada

77 JOHANSEN, Leif. Lectures on Macroeconomic Planning. Part 1: General Aspects. Amsterdam: North-Holland, 1977, p. 144, citando ELSTER, Jon. Excessive Ambitions. Capitalism and Society, Vol. 4, 2, 2009, p. 5.

${ }^{78}$ Kraus e Raso fazem uma sugestão similar no contexto da revisão judicial das decisões da Securities and Exchange Commission (SEC). Cf. KRAUS, Bruce; RASO, Connor. Rational Boundaries for SEC Cost-Benefit Analysis. Yale Journal on Regulation, Vol. 30, 2, 2013, p. 43-44.

${ }^{79}$ McKENZIE, Richard. On the Methodological Boundaries of Economic Analysis. Journal of Economic Issues, Vol. 12, 3, 1978, p. 635. Uma sugestão útil é que agências devem empregar regras experimentais destinadas a gerar informações. Cf. GUBLER, Zachary. Experimental Rules. Boston College Law Review, Vol. 55, 1, 2014; e LEE, Yoon-Ho Alex. An Options Approach to Agency Rulemaking. Administrative Law Review, Vol. 65, 4, 2013. Mas a sugestão não chega completamente a lidar com o problema. Dada a presença de sérias incertezas, de que forma deve ser definida a regra experimental? A decisão sobre essa questão terá, inevitavelmente, uma qualidade arbitrária. 
num ambiente informacionalmente incerto. "O Serviço [Fish and Wildlife Service]", escreveu a Corte, "deve explicar racionalmente por que a incerteza concernente ao impacto da redução de pinheiros-brancos em ursos pardos aconselha em favor do desalistamento agora, ao invés, por exemplo, da realização de mais estudos. Caso contrário, poderíamos estar deferindo também a um jogo de 'cara ou coroa'" . ${ }^{80}$ Entretanto, sob uma incerteza genuína, tais razões não podem ser antecipadas. A escolha de um ponto de parada será, necessariamente, arbitrária em um sentido de primeira ordem, embora deva haver algum ponto de parada. Interromper a busca por informações adicionais, em um ponto ou em outro, não é arbitrário de modo algum, desde que existam razões de segunda ordem perfeitamente boas para esse comportamento da agência. (E uma questão distinta se, ao interromper seu processo de coleta de informações, a agência deveria ou não ter decidido desalistar o urso pardo; abordei essa questão anteriormente). Como a sombra da regressão infinita se aproxima, tribunais devem deixar que agências desfiram um tiro no escuro, ao menos quando não houver evidência nos registros sugerindo que a incerteza possa ser dissipada a um baixo custo.

Não defendo uma total abdicação judicial, porque a qualificação que ofereci é real: agências deixam, às vezes, de investir em informações, cujos custos são justificados, que dissipariam a incerteza. Um exemplo vem de um caso sobre o Glacial Bay National Park and Preserve no Alaska. ${ }^{81}$ No âmbito da NEPA, a questão era se o National Parks Service tinha de preparar uma EIS completa a fim de avaliar os possíveis danos - para espécies ameaçadas ou em risco de extinção, para a qualidade do ar e para outros assuntos - decorrentes do aumento do número de transatlânticos autorizados a navegar na baía. ${ }^{82}$ Deixando de lado as particularidades do caso, a corte começou com o pé errado ao anunciar o princípio geral de que a "preparação de uma EIS é obrigatória quando a incerteza puder ser resolvida por meio da coleta adicional de dados". ${ }^{83}$ É verdade que há sempre chance de a incerteza ser resolvida pela coleta adicional de dados. Mas também há chances de não ser. Precisamente, o dilema é que, onde houver incerteza genuína em nível de segunda ordem, ou maior, não é certo se a incerteza de primeira ordem será resolvida pela coleta adicional de informações e, portanto, é analiticamente obscuro que preço pagar para isso.

Não obstante, com base nos fatos do caso em tela, a corte estava

${ }^{80}$ Cf. Greater Yellowstone Coalition, Inc. v. Servheen, 665 F. 3d 1.015, 1.028 (9th Cir., 2011).

${ }^{81}$ Cf. National Parks \& Conservation Ass'n v. Babbitt, 241 F. 3d 722 (9th Cir., 2001).

82 [N.T.] Por uma tradução livre, trata-se do Serviço de Parques Nacionais.

${ }^{83}$ Cf. National Parks \& Conservation Ass'n v. Babbitt, 241 F. 3d 722, 732 (9th Cir., 2001). 
predisposta a exigir do serviço de parques a preparação de uma EIA. Os detalhes são desnecessários. Basta dizer que o próprio registro demonstrou, conclusivamente, que existiam estudos de baixo custo que a agência poderia ter feito para dissipar a incerteza. ${ }^{84} \mathrm{Em}$ outras palavras, o caso era um exemplo de incerteza de primeira ordem, sem incerteza de segunda ordem. No problema dos cogumelos, descrito anteriormente, se os pedestres pudessem, pagando um centavo, receber um mapa com a localização dos cogumelos, haveria um passo, justificado por seus custos, que eles poderiam dar a fim de dissipar a incerteza de primeira ordem. Portanto, não haveria incerteza na segunda ordem. ${ }^{85} \mathrm{O}$ serviço de parques, no caso Glacier Bay, estava na mesma posição e sua recusa em se submeter aos estudos relevantes era genuinamente irracional. A Corte estava correto ao pesar a mão.

\section{DECISÕES RACIONALMENTE ARBITRÁRIAS}

Minha maior temática tem sido que, na presença da incerteza, o Direito Administrativo precisa abrir espaço para a tomada de decisões de agências que sejam racionalmente arbitrárias. Duas distinções são cruciais: em primeiro lugar, a diferença entre arbitrariedade na teoria da decisão e no sentido jurídico e, em segundo lugar, a diferença entre teorias normativas e descritivas da tomada de decisão sob incerteza. À luz dessas distinções, meus argumentos são que algumas decisões são racionalmente arbitrárias no sentido teórico-decisional, mas não devem contar como arbitrárias e caprichosas dentro dos termos da APA, e que decisões racionalmente arbitrárias são, por vezes, normativamente apropriadas, independentemente de pessoas (ou agências) as tomarem e de tribunais permitirem que elas sejam tomadas. Discutirei esses argumentos, considerarei o que tribunais podem fazer se estiverem desconfiados de que as agências invocam a incerteza como pretexto e, em

${ }^{84}$ Cf. National Parks \& Conservation Ass'n v. Babbitt, 241 F. 3d 722, 732-733 (9th Cir., 2001).

${ }^{85}$ É tentador pensar que o valor do próprio mapa precise ser incerto antes de examinarmos seu conteúdo, de modo que a regressão infinita da coleta de informação sempre se ocorra. Eu acho que isso é falso, no entanto. Pode-se ter conhecimento extrínseco suficiente das credenciais e das habilidades do cartógrafo, ou experiência suficiente com seus antecedentes em outras ocasiões, para ter confiança de que o mapa conterá informações úteis, mesmo sem inspecioná-lo. A regressão infinita da coleta de informações é uma possibilidade, mas não uma necessidade. 
seguida, abordarei a questão descritiva de como as cortes realmente abordam tais problemas.

\section{Incerteza: uma solução institucional}

Às vezes, agências têm excelentes razões de segunda ordem para tomar uma decisão em determinado tópico, incluindo-se um conjunto importante de casos em que o Direito ordena uma decisão imediata ao invés de postergada. Contudo, mesmo quando essa excelentes razões existem, também pode ser o caso de não ser possível oferecer qualquer razão de primeira ordem para tomar uma decisão relevante, de uma forma ou de outra, ou mesmo de adotar premissas otimistas ou pessimistas que influenciem a decisão. Por ser genuína, a incerteza knightiana apresenta casos dessa ordem. Nesses casos, o Direito não precisa adotar uma concepção limitada e errônea de racionalidade, algo que exige das agências a tarefa impossível de dar justificativas em matérias cujos poderes da razão se esgotaram.

A lógica também pode ser aplicada a decisões sobre quando coletar informações adicionais antes de tomar uma decisão substantiva - isto é, em decisões sobre interrupção ótima em situação de incerteza. Às vezes, há uma regressão infinita de incerteza acerca da quantidade de informações a se coletar antes de decidir a quantidade de informações a ser coletada, e assim por diante. Onde isso ocorre, não há alternativas senão cessar a coleta de informações em algum ponto arbitrado e tomar dar um "tiro no escuro". .6

A APA não reconhece qualquer categoria de decisões que sejam arbitrárias e caprichosas, porém, legalmente admissíveis. Nos termos da lei, cortes "devem... refrear a ausência de amparo legal e afastar" ações da agência que sejam "arbitrárias". ${ }^{87}$ Todavia, não significa que toda decisão racionalmente arbitrária, na teoria da decisão, também precise contar como arbitrária no sentido jurídico. ${ }^{88} \mathrm{Em}$ vez disso, tribunais

${ }^{86}$ Cf. McKENZIE, Richard. On the Methodological Boundaries of Economic Analysis.

Journal of Economic Issues, Vol. 12, 3, 1978.

${ }^{87}$ Cf. Administrative Procedure Act (APA) [Lei do Processo Administrativo], 5 U.S.C. 706

(2)(A) (2006).

${ }^{88}$ Para uma distinção um tanto diferente entre dois sentidos de arbitrariedade, cf.

Hoctor v. U.S. Department of Agriculture, 82 F. 3d 165, 170 (7th Circ., 1996), Judge Posner:

“No outro extremo daquilo que se poderia chamar de interpretação normal ou rotineira, está a produção de regras razoáveis, porém arbitrárias (não no sentido 
podem e devem concluir que decisões racionalmente arbitrárias contam como adequadamente motivadas para os propósitos do Direito Administrativo, quando e na medida em que tais decisões repousarem sobre razões de segunda ordem que lhes sejam válidas, mesmo quando as razões de primeira ordem se esgotarem.

De acordo com essa abordagem, tribunais teriam deferência para algumas escolhas das agências sob incerteza que nem sequer pretendem se basear em razões de primeira ordem - até mesmo para "cara ou coroa", como discutirei em breve. $\mathrm{O}$ dilema da tomada de decisão sob incerteza genuína seria resolvido institucionalmente, mais pela alocação do poder para tomada de decisão arbitrária entre os Poderes do Estado do que pelo raciocínio de primeira ordem. Cortes parecem desconfortáveis com esse tipo de solução puramente institucional, por motivos que também discutirei. Porém, se não houver uma base normativa válida para essa reação, o desconforto judicial é meramente um mau hábito que o sistema legal deve ignorar ou suprimir, em vez de perdoar.

\section{Como agências devem decidir?}

A solução institucional, em que tribunais permitem que agências tomem decisões arbitrárias sob incerteza, não aborda diretamente como as agências devem decidir. $\mathrm{Na}$ natureza do caso, onde prevalece a incerteza genuína, nenhum método decisório pode ser comprovadamente o melhor. No entanto, é possível mencionar algumas abordagens que sensatos tomadores de decisão usam mais ou menos conscientemente em situação de incerteza, mesmo que essas abordagens não possam ser totalmente justificadas por razões de primeira ordem. No artigo que citei na epígrafe, Keynes esboçou várias dessas abordagens, descrevendo-as como dispositivos que "[salvam] nossas peles enquanto homens racionais e econômicos". 89

Extrapolação. Pode-se decidir presumindo que o futuro será como o presente, ignorando nosso alto grau de confiança de que, na verdade, o futuro será diferente do presente de maneiras imprevisíveis. ${ }^{90} \mathrm{~A}$ intuição

"arbitrário ou caprichoso"), que são consistentes com legislação ou regulamentos sob os quais tais regras são construídas, mas não derivadas deles, porque representam uma escolha arbitrária entre os métodos de implementação."

${ }^{89}$ KEYNES, John Maynard. The General Theory of Employment. The Quarterly Journal of Economics, Vol. 51, 2, 1937, p. 214.

${ }^{90}$ KEYNES, John Maynard. The General Theory of Employment. The Quarterly Journal of Economics, Vol. 51, 2, 1937. 
deve ser aquela, segundo a qual, onde o futuro possa desviar em qualquer direção, nenhuma direção particular tem qualquer prioridade sobre uma simples extrapolação linear do presente.

Status Quo Padrão. Onde houver uma escolha entre fazer alguma coisa e não fazer nada, pode-se decidir não fazer nada, alegando que qualquer mudança do status quo incorre em custos de transição apenas por ganhos especulativos e obscuros. Esta é uma aplicação do raciocínio padrão, conforme discutido anteriormente.

Julgamento convencional. Esse é o termo de Keynes para o conformismo individualmente racional, em que, "considerando que nosso julgamento individual é desprezível, empenhamo-nos em recuar para o julgamento do resto do mundo, que, talvez, seja mais bem informado. Ou seja, esforçamo-nos para nos conformarmos com o comportamento da maioria ou da média".$^{91}$ Contudo, se outros também usarem a mesma estratégia, podem surgir cascatas informacionais e a informação transmitida a nós pelas decisões dos outros pode ser tão desprezível quanto a informação transmitida aos outros por nossa decisão. ${ }^{92}$ Independentemente do quão individualmente racional o conformismo puder ser, a nível de grupo, o resultado é "uma sociedade de indivíduos, cada um dos quais está se esforçando para copiar os outros". ${ }^{93}$

Randomização. O problema dos métodos de tomada de decisão examinados por Keynes não é que eles sejam errados, mas que são seriamente incompletos, ao menos enquanto aplicados à escolha de políticas públicas por agências. Há um conjunto de decisões de agências não triviais e, de fato, absolutamente importantes, no qual nenhum dos métodos de Keynes se ajusta confortavelmente. A extrapolação pode ser inoportuna se o problema não for (totalmente) de previsão, como quando o problema da agência é, precisamente, haver incerteza no real estado de coisas. Também assim, usar o status quo como padrão não funcionará se o Direito exigir da agência que tome uma nova decisão, de uma forma ou de outra, de modo que a não-regulação não seja uma opção - como quando a Endangered Species Act exige da agência que decida se, por certo tempo, uma espécie está, ou não, ameaçada ou em risco de extinção. $\mathrm{O}$

${ }^{91}$ KEYNES, John Maynard. The General Theory of Employment. The Quarterly Journal of Economics, Vol. 51, 2, 1937, p. 214.

${ }^{92}$ Cf. EASLEY, David; KLEINBERG, Jon. Networks, Crowds and Markets: Reasoning about a Highly Connected World. Cambridge, MA: Cambridge University Press, 2010

${ }^{93}$ KEYNES, John Maynard. The General Theory of Employment. The Quarterly Journal of Economics, Vol. 51, 2, 1937, p. 214. 
conformismo racional pode funcionar em configurações de mercado, ou em outros contextos, com um grande número de tomadores de decisão similarmente situados, tomando decisões similares, mas será inoportuno onde a decisão tiver características particulares e se restringir a uma agência em particular.

Nessas circunstâncias, não há razão para que a randomização não esteja no conjunto de ferramentas decisórias das agências. ${ }^{94}$ Dois tipos de casos fazem o "cara ou coroa" mais atrativos. Em alguns casos, o "cara ou coroa" pode proporcionar um desempate totalmente neutro e imparcial entre opções onde não há outro motivo para escolha, como quando uma eleição apertada é decidida aleatoriamente. Em outros casos, a randomização reduz os custos de decisão, incluindo-se, nestes custos, os custos de oportunidade do atraso e os danos colaterais positivos - aos litigantes ou a terceiros - dos próprios procedimentos necessários para solucionar a incerteza. Em outras palavras, a randomização é perfeitamente sensata quando for genuinamente incerto se mais procedimento e mais coleta de informação fariam as coisas melhor ou pior. Quanto às decisões de guarda de filhos, tem sido argumentado, muito plausivelmente, que o exato benefício de conceder a guarda ao melhor dos ascendentes pode, com frequência, ser bem menor do que o dano que uma prolongada disputa legal inflige à criança. Sendo assim, jogar "cara ou coroa" para conceder a guarda, logo no início, pode ser o melhor procedimento possível de tomada de decisão. ${ }^{95}$

Ambos os casos têm aplicações plausíveis para a tomada de decisão de agências. Para um exemplo do primeiro caso, suponhamos que a agência tem de decidir se o número existente de lagartos-de-chifres de cauda achatada é alto ou baixo, embora não haja qualquer método disponível para avaliar esse número que possua alguma validade a mais do que consultar um mapa astral. Por que não lançar a moeda? A agência terá de adivinhar de qualquer maneira e lançar moeda pelo menos tem a virtude da imparcialidade. O palpite da agência será, pelo menos, genuinamente aleatório, não influenciado por favoritismos

${ }^{94}$ Keynes não menciona o lançamento de moedas como uma estratégia autoconsciente para tomar decisões sob incerteza, embora seja justo dizer que suas referências aos espíritos animais implicitamente incorporam alguma noção de que há um elemento irredutível na chance de escolha sob incerteza.

${ }^{95}$ Cf. ELSTER, Jon. Solomonic Judgments: Studies in the Limitations of Rationality. Cambridge, MA: Cambridge University Press, 1989; e MNOOKIN, Robert. ChildCustody Adjudication: Judicial Functions in the Face of Indeterminacy. Law and Contemporary Problems, Vol. 39, 3, 1975. 
subconscientes ou preferências ideológicas. ${ }^{96}$

Para um exemplo do segundo caso, suponhamos que a agência precisa decidir se instalará uma certa medida precaucionária contra terrorismo em uma usina nuclear. Suponhamos, ainda, que é incerto - em sentido amplo - se uma investigação mais aprofundada da questão reduzirá o risco ou, ao contrário, se ele aumentará por alertar potenciais terroristas para a vulnerabilidade do alvo. Pelas mesmas razões que no caso da guarda da criança, parece perfeitamente sensato que a agência, agora, lance uma moeda para decidir se deve prosseguir com a medida em consideração, muito mais do que continuar no caminho de um processo que pode, como todos sabem, revelar-se desastrosamente contraproducente.

A sugestão não é, definitivamente, que lançar a moeda seja sempre um meio válido de tomada de decisão, mesmo sob incerteza. Em Judulang v. Holder (2012), no voto escrito pela Justice Kagan e citado, na epígrafe, o problema parece ter sido que o critério pelo qual o Board of Immigration Appeals se propôs a decidir não estava "ajustado, ainda que vagamente, aos propósitos da legislação migratória" ${ }^{97}$ Essa não é uma descrição válida do tipo de casos que abordei, em que uma agência, inteiramente focada nos objetivos das leis que administra, alcança, porém, uma fronteira de incerteza em que razões de primeira ordem para fazer escolhas à luz de tais objetivos simplesmente se esvaem, embora as escolhas devam ser feitas de alguma forma. Nesses casos, a randomização deveria ser um modo perfeitamente aceitável de proceder, entre os outros modos que discuti anteriormente. Não está claro se Judulang v. Holder (2012) espera condenar todo lançamento de moedas de agências, mas há uma leitura mais restrita do voto que deixa em aberto o argumento que ofereci.

\section{Incerteza, pretexto e inconsistência}

Uma preocupação válida para o Direito, e uma preocupação que

${ }^{96}$ Cf. FCC v. Fox Television Stations, Inc., 556 U.S. 502, 549 (2009), Justice Breyer, dissentindo: "Um administrador (imaginário) explicando por que ele escolheu uma política que exige dirigir do lado direito, ao invés do lado esquerdo, da estrada poderia dizer: 'Bem, um lado parecia tão bom quanto o outro, então, eu joguei cara e coroa.'” Breyer, no entanto, nega que um "cara ou coroa" seria um raciocínio suficiente para mudar a política original.

${ }^{97}$ Cf. Judulang v. Holder, 132 S. Ct. 476, 485 (2012). 
alguns juízes provavelmente sustentam, é que as agências invocam a incerteza como pretexto ou inconsistentemente, usando-a para justificar escolhas feitas disfarçadamente por motivos ilegítimos - favoritismo político, preferência ideológico, simples evasão, ou coisas do gênero. Talvez, agências alegarão que a situação é de incerteza quando, em verdade, é de risco; talvez, agências sejam preguiçosas demais para calcular os riscos relevantes ou temam que, fazendo isso, produziriam resultados inconvenientes e os deixariam óbvios demais para as cortes revisoras e, similarmente, por premissas particulares sob incerteza. Talvez, uma agência adotará premissas otimistas sobre se a população de uma espécie ameaçada de extinção é incerta apenas porque a agência tem um desgosto ideológico pelas leis de espécies ameaçadas; talvez, as agências sejam inconsistentes através dos casos, adotando ambas as premissas otimistas ou pessimistas como necessárias para promover seus objetivos políticos.

Embora essas preocupações sejam válidas, elas não estão particularmente relacionadas às alegações de incerteza das agências. Pretexto e inconsistência são problemas gerais da tomada de decisão das agências, seja sob incerteza, risco, ou, para esse assunto, certeza. Se uma agência alega que uma determinada decisão é justificada por uma análise ordinária de risco, de tal forma que o projeto relevante tenha firmado probabilidades de ganhos, a agência pode, na realidade, estar motivada por favoritismo político ou preferência ideológico. Talvez, a agência até descreva a situação como de risco quando é, efetivamente, de incerteza, para dar uma falsa aparência de determinação científica à sua decisão. $\mathrm{O}$ problema da charada científica é ortogonal à distinção entre risco e incerteza. ${ }^{98}$

Assim, a preocupação com o pretexto ocorre em sentido amplo, muito além do domínio da incerteza e muito além de qualquer dos métodos de tomada de decisão sob incerteza mencionados anteriormente. Suponhamos que a agência alegue ter jogado uma moeda e atingido o resultado $X$, onde $X$ é ideologicamente conveniente para a agência, mas $Y$ não seria. A corte pode ficar desconfiada de que a agência esteja mentindo e de que ela nunca fez qualquer randomização efetivamente. (Sendo assim, a corte pode demandar que o "cara ou coroa" aconteça em sua presença.) Todavia, a agência também poderia mentir em muitos outros casos, não havendo qualquer relação com randomização ou incerteza. Ela poderia estar mentindo sobre seus motivos para construir uma nova política ou para autorizar a abdicação de uma regra antiga. Os

${ }_{98}$ Cf. WAGNER, Wendy. The Science Charade in Toxic Risk Regulation. Columbia Law Review, Vol. 95, 7, 1995. 
métodos habituais para expor os motivos reais de uma agência envolvem técnicas como ordenar que ela tome decisões em um registro formal, ordenar que ela responda especificamente a comentários, mesmo que não haja registro formal, permitir o questionamento cruzado dos especialistas de uma agência e verificar a compatibilidade entre as constatações da agência e suas conclusões. Esses métodos também podem ser tão bem, ou tão deficientemente, aplicados às decisões de agências em situação de incerteza, quanto a outros tipos de decisões.

O mesmo se aplica à inconsistência. É um problema central no Direito Administrativo se, e em que medida, as agências têm uma obrigação de consistência, através de casos ou regras, nas razões que conferem e nas interpretações jurídicas que oferecem. ${ }^{99} \mathrm{~A}$ incerteza não tem nada de único nesses casos. Se, e na medida em que, as agências têm uma obrigação de consistência através de casos e decisões, então, essa obrigação deve se estender à escolha das premissas para a incerteza, mas essa é uma questão muito mais ampla.

\section{Do normativo ao descritivo}

Nada do que tratei foi destinado a oferecer qualquer argumento descritivo sobre como agências e cortes se comportarão de fato ou com que fundamentação eles, efetivamente, tomarão suas decisões. Como agências e cortes decidem quando a incerteza é tão grave que as razões de primeira ordem se esgotam? Em alguns casos, os tomadores de decisão de agências podem selecionar conscientemente entre opções, em vez de tentar escolher entre elas de uma forma completamente racional. ${ }^{100}$ Mecanismos randomizadores podem ser, mas nunca são, usados para selecionar, provavelmente porque tribunais - por motivos que mencionarei em breve - são implacavelmente hostis à randomização. Em outros casos, tomadores de decisão de agências podem, erroneamente, acreditar que têm boas e suficientes razões de primeira ordem para suas escolhas, quando, de fato, a incerteza implica que essas razões não sejam conclusivas ou possam ser combatidas por argumentos igualmente bons em direção oposta. Quando isso ocorre, do ponto de vista do analista, agências decidirão, de fato, como se estivessem randomizando sobre as

${ }^{99}$ Cf. GIVATI, Yehonatan; STEPHENSON, Matthew. Judicial Deference to Inconsistent Agency Statutory Interpretations. Journal of Legal Studies, Vol. 40, 1, 2011.

${ }^{100}$ Cf. ULLMANN-MARGALIT, Edna; MORGENBESSER, Sidney. Picking and Choosing. Social Research, Vol. 44, 4, 1977. 
opções incertas, mesmo se, subjetivamente, os tomadores de decisão da agência acreditarem estar tomando decisões inteiramente racionais em um sentido de primeira ordem. As intuições, os preconceitos e os espíritos animais dos tomadores de decisão de uma agências determinarão, na prática, o quão otimistas ou pessimistas suas premissas podem ser, o quão rapidamente a agência interromperá a busca por informações adicionais e assim por diante. Não creio que haja qualquer objeção a tal situação. Embora possa ser melhor, sub specie aeternitatis, para oficiais da agência saber que estão, na verdade, randomizando ao redor de escolhas incertas, o sistema regulatório pode hesitar sem completo autoconhecimento de sua parte.

O que o sistema regulatório precisa, no entanto, é de um reconhecimento pelos tribunais dos limites da razão de primeira ordem. ${ }^{101}$ É prejudicial quando tribunais anulam decisões de agências por falta de razões de primeira ordem quando essas razões não podem ser fornecidas e onde a decisão contrária da agência poderia ter sido anulada por esse mesmo fundamento. A decisão judicial é, assim, uma espécie de perda de peso morto, que não pode, nem em princípio, melhorar a decisão, mas apenas pode forçar a agência a assumir um raciocínio epistemologicamente injustificado para o que é, essencialmente, uma decisão arbitrária, mas também racional. ${ }^{102}$

Muitos têm notado que cortes são hostis à randomização e, mais amplamente, tendem a demandar razões de primeira ordem mesmo quando tais razões não podem ser fornecidas. ${ }^{103} \mathrm{~A}$ cultura jurídica, que

${ }^{101}$ Para uma exploração do mesmo tema em configurações constitucionais, cf.

VERMEULE, Adrian. Law and the Limits of Reason. Oxford: Oxford University Press, 2009.

102 [N.T.] O autor se refere a um termo econômico pouco comum nas ciências jurídicas em geral: perda de peso morto. A expressão "perda" é utilizada no sentido oposto a "ganho", enquanto uma redução de receita. Já "peso morto" está relacionado a uma alocação ineficiente de recursos. Geralmente, o conceito é ilustrado pela introdução de tributos em mercados que haviam alcançado um equilíbrio entre oferta e demanda de determinado produto. Em tal situação, há menos consumidores dispostos a pagar o preço do produto, dependendo da elasticidade do mercado, e produtores deixam de lucrar parte do preço pago por eles em cada venda. O peso morto é a soma dos valores perdidos pelo produtor nesses dois aspectos (no número de vendas e no preço do produto). O autor parece ter empregado a expressão porque ela representa um resultado abaixo do ponto ótimo, que poderia ter sido alcançado - no sistema regulatório - se não houvesse interferência externa - pelo Judiciário.

${ }^{103}$ Cf. DUXBURY, Neil. Random Justice: on Lotteries and Legal Decision-Making. Oxford: Oxford University Press, 2002.

3 JOURNAL OF INSTITUTIONAL STUDIES 1 (2017) 
celebra a argumentação; uma premissa afim e inteiramente equivocada de que o Estado de Direito exige razões de primeira ordem para toda escolha; a necessidade de justificar decisões por uma linguagem racional para agentes de outros Poderes e para o público em geral; e a aversão à incerteza e à ambiguidade que juízes compartilham com outros seres humanos; tudo isso conspira para produzir hiperracionalismo judicial. Contudo, creio que há sementes, dentro do próprio Direito Administrativo, de uma visão mais ampla e esclarecida, segundo a qual o Estado de Direito se satisfará com razões de segunda ordem, ao menos quando as razões de primeira ordem se esgotarem. Demonstrei que a Suprema Corte, por várias vezes, advertiu tribunais inferiores por impor restrições excessivas à tomada de decisão de agências em situação de incerteza, reconhecendo que a atuação da agência nas fronteiras do conhecimento não deve ser revisada tão estritamente como sua confortável atuação dentro das fronteiras. ${ }^{104}$ Estruturalmente, tribunais e seus juízes são tão produtores de Direito, quanto revisores de decisões tomadas por outros, e isso pode incutir neles uma compreensão um tanto mais complacente dos dilemas enfrentados por tomadores de decisão em situação de incerteza. Não é inconcebível que tribunais reconheçam, algum dia, a existência de uma categoria de decisões que são arbitrariamente racionais - e, portanto, que não são nada arbitrárias no sentido jurídico.

\section{CONCLUSÃO: AS AGÊNCIAS NA FRONTEIRA DA INCERTEZA}

Nas décadas de 1960 e 1970, as agências federais enfrentaram um cenário político em que havia muitas decisões fáceis para tomar. Os rios estavam tão contaminados que pegavam fogo ${ }^{105} \mathrm{O}$ cenário não se parece mais com isso, tanto no sentido literal, quanto no figurativo. Muitos (não todos) problemas fáceis foram abordados e alguma crescente fração do que as agências fazem repousa na fronteira científica ou além dela, onde todos os problemas são difíceis. $\mathrm{O}$ arco do Estado Administrativo se curva em direção à incerteza.

Dito isso, tribunais fariam bem ao atenuar suas exigências por

${ }^{104}$ Cf. Baltimore Gas \& Electric Co. v. Natural Resources Defense Council, Inc., 462 U.S. 87 (1983); e Robertson v. Methow Valley Citizens Council, 490 U.S. 332 (1989).

105 Cf. STRADLING, David; STRADLING, Richard. Perceptions of the Burning River: Deindustrialization and Cleveland's Cuyahoga River. Environmental History, Vol. 13, 3, 2008. 
raciocínios de primeira ordem. À medida que agências se aproximam da fronteira da incerteza, haverá mais e mais casos em que a impiedosa demanda judicial por razões de primeira ordem será patológica e lesiva, forçando tomadores de decisão de agências a inventar razões, em que eles podem acreditar ou não, na prática, e que falharão cronicamente ao justificar suas decisões - deixando aberta a possibilidade de custosas reincidências judiciais para futuras rodadas de justificação, e assim por diante, ad infinitum. Nas atuais circunstâncias do Estado Administrativo, logo, é imperativo que o Direito deve reconhecer uma categoria de decisões de agências racionalmente arbitrárias.

\section{REFERÊNCIAS}

ALEXANDER, Kristina. Warranted but Precluded: What That Means under the Endangered Species Act (ESA). Congressional Research Service, CRS Report 7-5700, 2010.

AL-NAJJAR, Nabil I. A Bayesian Framework for the Precautionary Principle. Journal of Legal Studies, Vol. 44, S-2, 2015.

ARROW, Kenneth; HURWICZ, Leonid. An Optimality Criterion for Decision-Making under Ignorance. In: C.F. Carter; J.L. Ford (eds.). Uncertainty and Expectations in Economics: Essays in Honour of G.L.S. Shackle. Oxford: Oxford University Press, 1972.

BERTSIMAS, Dimitris; SIM, Melvyn. The Price of Robustness.

Operations Research, Vol. 52, 1, 2004.

CALABRESI, Guido; BOBBITT, Philip. Tragic Choices. New York, NY: W.W. Norton \& Company, 1978.

DIXIT, Avinash; PINDYCK, Robert. Investment under Uncertainty. Princeton, NJ: Princeton University Press, 1994. 
DUXBURY, Neil. Random Justice: on Lotteries and Legal DecisionMaking. Oxford: Oxford University Press, 2002.

EASLEY, David; KLEINBERG, Jon. Networks, Crowds and Markets: Reasoning about a Highly Connected World. Cambridge, MA:

Cambridge University Press, 2010.

ELSTER, Jon. Solomonic Judgments: Studies in the Limitations of Rationality. Cambridge, MA: Cambridge University Press, 1989.

. Excessive Ambitions. Capitalism and Society, Vol. 4, 2, 2009.

FARBER, Daniel. Uncertainty. Georgetown Law Journal, Vol. 99, 4, 2011.

FUDENBERG, Drew; MASKIN, Eric. The Folk Theorem in Repeated Games with Discounting or with Incomplete Information.

Econometrica, Vol. 54, 3, 1986.

GILBOA, Itzhak; SCHMEIDLER, David. Maxmin Expected Utility with a Non-Unique Prior. Journal of Mathematical Economics, Vol. 18, 2, 1989.

GIVATI, Yehonatan; STEPHENSON, Matthew. Judicial Deference to Inconsistent Agency Statutory Interpretations. Journal of Legal Studies, Vol. 40, 1, 2011.

GUBLER, Zachary. Experimental Rules. Boston College Law Review, Vol. 55, 1, 2014.

HALPERN, Joseph. Reasoning about Uncertainty. Cambridge, MA: MIT Press, 2005. 
JOHANSEN, Leif. Lectures on Macroeconomic Planning. Part 1:

General Aspects. Amsterdam: North-Holland, 1977.

KELSEY, David. Choice under Partial Uncertainty. International Economic Review, Vol. 34, 2, 1993.

KELSEY, David; QUIGGIN, John. Theories of Choice under Ignorance and Uncertainty. Journal of Economic Surveys, Vol. 6, 2, 1992.

KEYNES, John Maynard. The General Theory of Employment, Interest and Money. New York, NY: Harcourt, Brace, 1936.

KEYNES, John Maynard. The General Theory of Employment. The Quarterly Journal of Economics, Vol. 51, 2, 1937.

KNIGHT, Frank. Risk, Uncertainty and Profit. Boston: Houghton Mifflin Co., 1921.

KRAUS, Bruce; RASO, Connor. Rational Boundaries for SEC CostBenefit Analysis. Yale Journal on Regulation, Vol. 30, 2, 2013.

LEE, Yoon-Ho Alex. An Options Approach to Agency Rulemaking. Administrative Law Review, Vol. 65, 4, 2013.

MATTIX, Carla; BECKER, Kathleen. Scientific Uncertainty under the National Environmental Policy Act. Administrative Law Review, Vol. 54, 3, 2002.

McKENZIE, Richard. On the Methodological Boundaries of Economic Analysis. Journal of Economic Issues, Vol. 12, 3, 1978.

MELBERG, Hans. A Critical Discussion of Jon Elster's Arguments about Rational Choice, Infinite Regress and the Collection of Information. 
Unpublished thesis. University of Oslo, Department of Economics, Oslo, 1999.

MNOOKIN, Robert. Child-Custody Adjudication: Judicial Functions in the Face of Indeterminacy. Law and Contemporary Problems, Vol. 39, 3, 1975.

STIGLER, George. The Economics of Information. Journal of Political Economy, Vol. 69, 3, 1961.

STRADLING, David; STRADLING, Richard. Perceptions of the Burning River: Deindustrialization and Cleveland's Cuyahoga River.

Environmental History, Vol. 13, 3, 2008.

SUNSTEIN, Cass. The Arithmetic of Arsenic. Georgetown Law Journal, Vol. 90, 7, 2002.

. Risk and Reason: Safety, Law, and the Environment.

Cambridge, MA: Cambridge University Press, 2002.

. Chevron Step Zero. Virginia Law Review, Vol. 92, 2, 2006.

. Worst-Case Scenarios. Cambridge, MA: Harvard University

Press, 2007.

SUNSTEIN, Cass; ULLMANN-MARGALIT, Edna. Second-Order

Decisions. Ethics, Vol. 110, 1, 1999.

ULLMANN-MARGALIT, Edna; MORGENBESSER, Sidney. Picking and Choosing. Social Research, Vol. 44, 4, 1977.

VERMEULE, Adrian. Law and the Limits of Reason. Oxford: Oxford University Press, 2009. 
. The Parliament of the Experts. Duke Law Journal, Vol. 58, 8, 2009.

WAGNER, Wendy. The Science Charade in Toxic Risk Regulation. Columbia Law Review, Vol. 95, 7, 1995.

WALD, Abraham. Statistical Decision Functions Which Minimize the Maximum Risk. Annals of Mathematics, Vol. 46, 2, 1945.

WEITZMAN, Martin. On Modeling and Interpreting the Economics of Catastrophic Climate Change. Review of Economics and Statistics, Vol. 91, 1, 2009.

WIENER, Jonathan Baert. Managing the Iatrogenic Risks of Risk Management. Risk: Health, Safety and Environment, Vol. 9, 1, 1998.

WINTER, JR., Sidney. Economic "Natural Selection" and the Theory of the Firm. Yale Economic Essays, Vol. 4, 1, 1964.

WOODWARD, Richard; BISHOP, Richard. How to Decide When Experts Disagree: Uncertainty-Based Choice Rules in Environmental Policy. Land Economics, Vol. 73, 4, 1997.

YOHE, Gary; TOL, Richard. Precaution and a Dismal Theorem: Implications for Climate Policy and Climate Research. Working Paper FNU, No. 145, 2007.

Decisões Racionalmente Arbitrárias no Direito Administrativo Rationally Arbitrary Decisions in Administrative Law Submetido em: 2017-05-16 Aceito em: 2017-07-30 